\title{
THE EFFECT OF CALCIFIED PLAQUE ON STRESS WITHIN A FIBROUS THIN CAP ATHEROMA IN AN ATHEROSCLEROTIC CORONARY ARTERY USING FINITE ELEMENT ANALYSIS (FEA)
}

\author{
A Thesis \\ Presented to \\ the Faculty of California Polytechnic State University, \\ San Luis Obispo
}

\author{
In Partial Fulfillment \\ of the Requirements for the Degree \\ in Master of Science in Engineering, with Specializations \\ in Biomedical Engineering
}

By

Ellerie Nagy

June 2008 
(C) 2010

Ellerie Nagy

ALL RIGHTS RESERVED 


\section{COMMITTEE MEMBERSHIP}

TITLE:

The Effect of Calcified Plaque on Stress within a Fibrous Thin Cap Atheroma in an Atherosclerotic Coronary Artery Using Finite Element Analysis (FEA)

AUTHOR: $\quad$ Ellerie Nagy

DATE SUBMITTED: SEPTEMBER 2010

COMMITTEE CHAIR: Dr. David Clague, Ph.D.

COMMITTEE MEMBER: Dr. Robert Crockett, Ph.D.

COMMITTEE MEMBER: Dr. Kristen O'Halloran Cardinal, Ph.D. 


\begin{abstract}
The Effect of Calcified Plaque on Stress within a Fibrous Thin Cap Atheroma in an Atherosclerotic Coronary Artery Using Finite Element Analysis (FEA)

Ellerie Nagy
\end{abstract}

Atherosclerosis causes hundreds of thousands of deaths in the US alone every year. Fibrous cap rupture is one of the leading causes of these fatalities. Thin cap atheromas are commonly regarded as vulnerable plaque, however the effect of calcium upon a thin fibrous cap with lipid pool is poorly understood. Some studies have shown that calcium adds to stability of the lesion, while others have proven otherwise. An article by Li et al. 2007 suggests location is the key factor. By varying the percentage of calcium and lipid within a defined region, the stress on the cap was estimated using an idealized finite element arterial model. Also the thickness of the fibrous cap was varied to determine whether the stress was solely a function of lipid percentage or a combination. Plaque, arterial wall, lipid, and calcium were modeled using linear elastic, isotropic, and incompressible material properties. The first test varied the thin cap thickness from 65 to 500 microns and tested the calcified lipid model at varying lipid/calcium percentages. The lipid/Calcium pool increased/decreased 10\% each test. As the cap thickness becomes thinner than 100 microns, the stress level increases rapidly. The second test compared a model with lipid pool and calcium behind the lipid with a thin cap of 65 microns to a model with lipid pool of the same size and thin cap of 65 microns but only fibrous tissue surrounding (no calcium). The lipid pool increased from 10 to $90 \%$ lipid. The result of this test found that at higher lipid percentages, the calcium increased the stress on the cap. By understanding the material properties of plaque and the structure of the lesion, future developments may be able to evaluate rupture risk. This idealized study illustrates the ability of computation models to provide insight into clinical situations.

Keywords: Atherosclerosis, Thin Cap Atheroma, Finite Element Analysis, Calcified Plaque 


\section{ACKNOWLEDGMENTS}

I would like to thank my thesis teammate Anita Crompton. This project would have been a complete struggle without your help. I would like to thank Dr. David Clague, Dr. Bob Crockett, and Dr. Kristen Cardinal, my thesis committee, for their assistance and flexibility. None of this project would have been possible without your expert guidance. 


\section{TABLE OF CONTENTS}

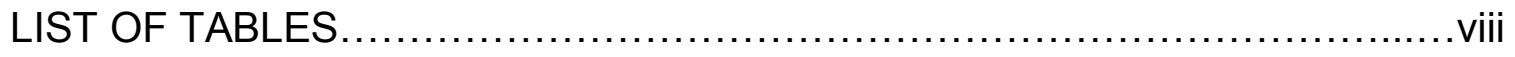

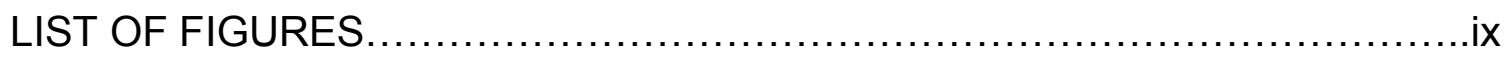
CHAPTER

I.

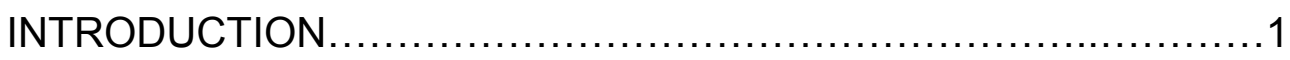

Defining Atherosclerosis .........................................

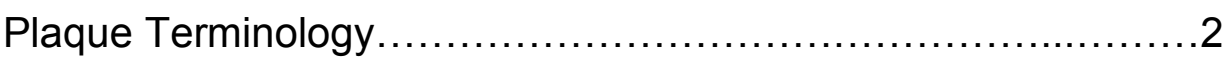

Classifications of Atherosclerosis............................... 5

Other Factors that Affect Atherosclerosis........................10

Plaque Rupture: Mechanisms and Thrombi ......................11

Demand and Complexities in Standardizing Vulnerable

Plaque Risk..............................................15

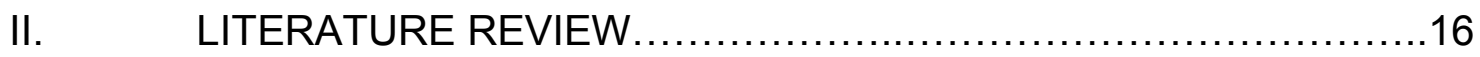

Finite Element Analysis (FEA) and Atherosclerosis...............16

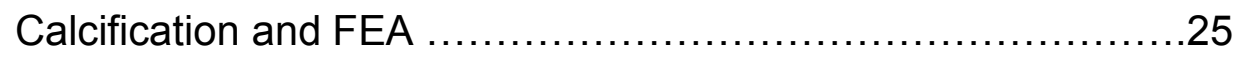

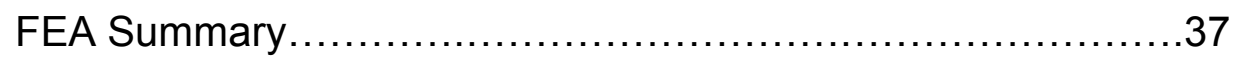

III. METHOD OF INVESTIGATION....................................39

Using FEA to Determine the Interaction of Fibrous Cap Thickness, Lipid Pool Area, and Calcification on Peak

Stresses................................................... 39

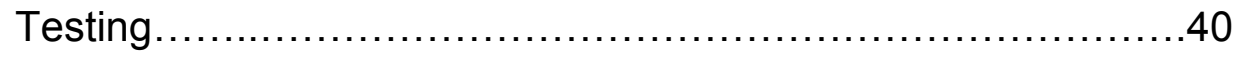

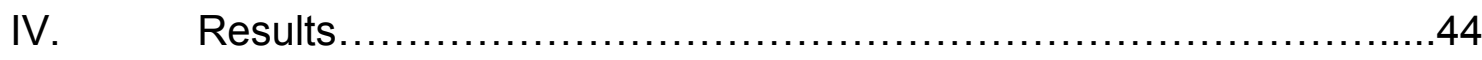

V. Discussion and Interpretation .................................... 48 


\section{APPENDICES}

A: Future Direction Possibilities for FEA analysis......................50

B. Future Directions of Predicting Rupture Risk .........................51

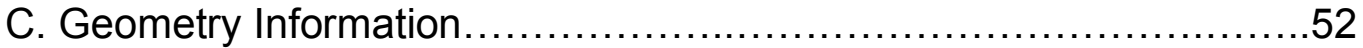

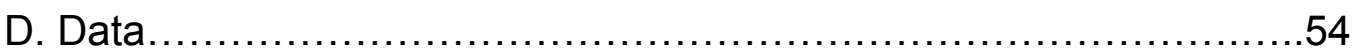

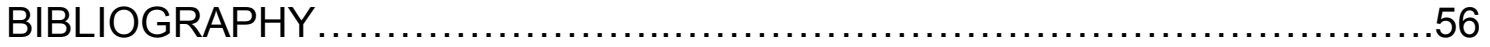


Table

\section{LIST OF TABLES}

1. Material Parameters for Plaque and Artery used in Finite Element Models for Change et al................................................ 19

2. Material Parameters for Plaque and Artery used in Finite Element Analysis for Baldewsing et al.

3. Ogden Material Parameters for Plaque and Artery in the Finite Element Model for Li et al.

4. Mooney Rivlin Constants Used in Huang et al. ...........................28

5. Mooney-Rivlin Constants used in Tang et al. ...........................29

6. Linear Elasticities used in Veress et al. ...................................32

7. Material Properties Used in this Study ..................................42

8. Lipid/Calcium Dividing Line ...........................................53

9. Stress Values (Pa): 65 um Cap Thickness...............................54

10. Stress Values (Pa): 150 um Cap Thickness..............................54

11. Stress Values (Pa): $250 \mu \mathrm{m}$ Cap Thickness.............................54

12. Stress Values (Pa): 500 um Cap Thickness.............................54

13. Stress Values $(\mathrm{Pa}): 90$ um Cap Thickness...............................55

14. Stress Values (Pa): 120 um Cap Thickness..............................55

15. Stress Values (Pa): Compiled Average Stress Values....................55

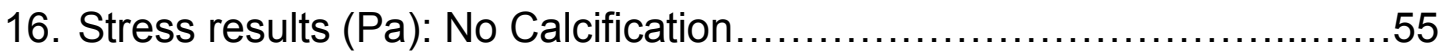




\section{LIST OF FIGURES}

Figure

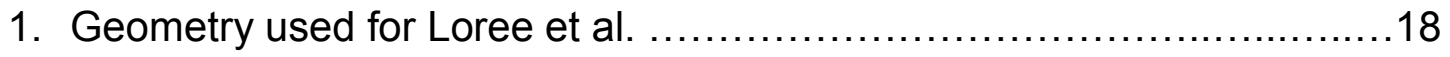

2. The Stress on the Fibrous Cap as a Function of Cap Thickness............18

3. The six idealized MRI models from Cheng et al..........................22

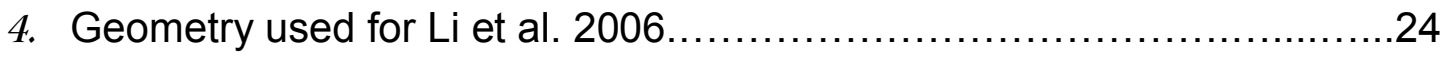

5. Plaque stress variation within $40 \%$ and $50 \%$ stenotic arteries as a function of fibrous cap thickness..........................................24

6. Effect of the fibrous cap thickness on plaque stress at different degrees of luminal stenosis. ........................................... 25

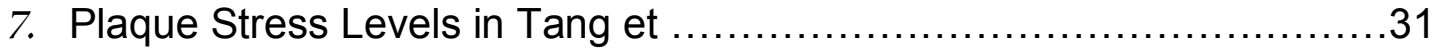

8. $8 \mathrm{a}, 8 \mathrm{~b}$. Schematic images of the two different ideal plaque

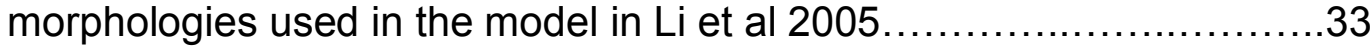

9. The idealized atheromatous plaque model from Li et al $2007 \ldots \ldots \ldots \ldots . . . .35$

10. Three Plaques with Varying Calcium Location in Li et al. 2007 ............35

11. Four Geometric Diagrams .............................................. 41

12. Variations in Peak Stress at Differing Fibrous Cap Thicknesses ...........44

13. Peak Stresses at Various Cap Thicknesses ...............................45

14. Overview of Peak Stress Data ......................................... 46

15. Peak Stress Comparison of Calcified and Noncalcified FEMs ............46

16. Basic Geometry Measurements for Construction in Comsol...............52

17. Geometries of all models (shown with a 150 micron cap) from $0 \%$ to $100 \%$ lipid with $10 \%$ increments 


\section{Chapter 1: INTRODUCTION}

\section{Defining Atherosclerosis}

According to the American Heart Association (AHA), atherosclerosis is a "process in which deposits of fatty substances, cholesterol, cellular waste products, calcium and other substances build up in the inner lining of an artery." These alternate substances are better known as plaque. Plaque can narrow the arteries causing complications in the vascular system. Fatty build-ups of plaque can result in angina pectoris (chest pain), plaque rupture, and heart attack. Coronary Heart Disease (CHD) is caused by atherosclerosis.

The AHA claims that CHD claimed 451,326 deaths in 2004. Despite the rate of coronary heart disease declining 33\% form 1994 to 2004, CHD remains the single leading cause of death in America today. The AHA also estimates that 1.2 million Americans will have new or recurrent coronary attacks this year. The AHA alone spent around $\$ 544$ million dollars in the fiscal year 2005-2006 on research support, professional and public education, and community service programs.

A healthy coronary artery is comprised of three layers: the intima, the media, and the adventitia. The inner most layer, the intima is composed mainly of endothelial cells. This thin layer of cells forms an interface between the lumen of the artery and the circulating blood. The endothelial cells prevent thrombosis and inflammation. The media, or tunica media, is the bulky middle layer of an artery which is composed predominately of smooth muscle cells. The adventitia, also 
known as the tunica externa, is the outmost layer of the artery. It is composed mainly of collagen which provides stability and helps aid connections to the organs it supports.

Atherosclerosis is typically characterized by thickening of the arterial wall composed of fibrous tissue, lipid deposits, and calcium deposits. Mostly the media and endothelial layers are affected. On a microbiological level, unhealthy arteries have the following characteristics: they contain macrophage foam cells, lipid-laden smooth muscle cells, a damaged endothelial lining and inflammation (Stary et al. 1995a). All these characteristics contribute to plaque.

\section{Plaque Terminology:}

Plaque was labeled "culprit plaque" in the past when it was responsible for coronary occlusion or death. However there wasn't a term that described plaque before an event occurred. Some pathologists in the early $20^{\text {th }}$ century began describing the event of thrombi dislodging as "plaque rupture"(Naghavi et al. 2003). Scientists in the 1960 s began to concentrate on plaque rupture. In the 1980s the term plaque disruption was interchangeable with plaque rupture. "Vulnerable plaque" was also used to describe rupture-prone plaques. At this time vulnerable plaques had the characteristics of having a large lipid pool, a thin fibrous cap between the lumen and lipid pool, and macrophage-dense inflammation on or beneath its surface (Naghavi et al. 2003).

According to Naghavi et al. (2003), recently "vulnerable plaque" has been used to describe high-risk atherosclerotic areas in relation to its histology and 
also to describe plaque that may lead to coronary events. According to the Webster dictionary "vulnerable" means "susceptible to injury or susceptible to attack" (Naghavi et al. 2003). Vulnerable plaque best describes plaques susceptible to complications. Additionally the terms "high-risk plaque", "dangerous plaque", and "unstable plaque" have been less commonly used to describe vulnerable plaques. Naghavi et al. (2003) argues that vulnerable should be used because it more appropriately describes patients that seem healthy but are at risk for future events. Naghavi et al. (2003) further argues that since vulnerable plaque has become widely accepted by the medical community, this usage should continue. However, Naghavi et al. (2003) does propose the need for a system of classifying plaques based on their underlying morphological features which can quantify the risk of thrombosis or the risk of rapid progression of cardiac events.

Maseri and Fuster (2003) wrote the article "Is There a Vulnerable Plaque?" with a differing view on the idea of plaque vulnerability. The term "Unstable plaque" was used to identify coronary plaque disruption and subsequent thrombosis. Disruption of unstable plaque causes a transition from coronary artery disease (CAD) to acute coronary syndromes (ACS) in which the artery occludes resulting in infarct. The group of researchers noted that high-risk blood is another key factor in thrombogenic states. The term "vulnerable" plaque was used by Muller in the late 80 s to describe post-mortem patients with ACS. Plaque with large lipid core, thin fibrous cap, and rupture was often found. Researchers hypothesized that rupture was caused by the force of shear stress 
from blood flow. Recent research has found that inflammatory mechanisms contribute plaque instability (Maseri and Fuster 2003). Plaque rupture can be due to a number of factors.

Maseri and Fuster (2003) emphasized that to detect and quantify vulnerability in plaque, plaque vulnerability needs a clear definition. Identifying plaque risk is complicated for many reasons. Vulnerable/high-risk plaques may become unstable because of structural or inflammatory vulnerability or because of other yet unknown causes. Multiple vulnerable plaques may be present in multiple coronary arteries. Vulnerable plaques may remain vulnerable for weeks, months or years without an event such as thrombosis, stroke, occlusion, or death. Vulnerable plaques come in differing compositions; they may be fibrotic, lipid, or endothelial in composition or a combination.

Since "vulnerable" plaque has been used in the past to describe the specific event of plaque rupture, "high risk" plaque would be a better term to describe the overall state of the diseased artery. This would imply that there isn't a single reason for the plaque to be unstable but a combination of reasons. Plaque may have a thin cap, a large lipid pool, and/or high inflammation among other factors which may cause instability (Maseri and Fuster 2003). With such a broad range of differing opinions, the fact remains that plaque vulnerability and plaque risk does not have clear interpretability. If a clear definition of plaque risk could be agreed upon, clinically plaque risk could be predicted and hopefully prevented. 


\section{Classifications of Atherosclerosis}

In order to quantify plaque rupture risk, terminology and categories of plaque must be agreed upon. While developing names for lesion types seems straightforward, researchers have differing opinions on a categorical strategy. Many have proposed a clinically standardized naming scheme for types of plaque. In 1995 a report for the AHA by H.C. Stary et al. (1995a,b) characterizes atherosclerosis into six categories. Type I, II, and III are non-serious types of lesions while types IV, V, and VI have the potential to be fatal.

Type I, II, and III are non-fatal categorizations of lesions. These can develop into more serious types of lesions. Although the types of lesions are not characterized as a linear chronological progression, Type I is classified as the initial lesion. This includes an increase in macrophages and macrophage foam cells due to atherogenic lipoproteins. These changes can be seen in their adaptive intimal thickening. Stary et al. (1995a) notes this thickening is a natural process occurring in arteries in everyone since birth. Type II lesions are characterized by fatty streaks. These consist of macrophage foam cells and lipidladen smooth muscle cells. Type III is an intermediate stage between stage II , fatty streaks, and IV which can lead to serious cardiac events. Unlike Type IV, Type III is non-threatening since the endothelial layer of the artery is healthy and lipid deposits are small enough so no threat of is imposed. These arteries have type II characteristics with additional scattered areas of extracellular lipid 
collections that accumulate between intimal smooth muscle cells (Stary et al. 1995a).

Type IV, V and VI are serious types of atherosclerosis. When the lipid deposits found in type III lesions grow larger, the artery is then classified as type IV lesions. This was later clarified the characteristics in 2000 with a follow up report. Type IV lesions can cause stenosis since the lipid pool determines the degree which the lumen is constricted. These lesions still have smooth muscle cells and do not have extensive fibrotic tissue. If the lipid begins to rapidly grow, this lesion can narrow the lumen and be at high risk for plaque rupture, sending a flood of lipid into the blood stream. This leads to clotting which can lead to coronary occlusion, stroke, or death. (Stary et al. 1995b).

Type $\mathrm{V}$ lesion is characterized by thick layers of fibrous tissue. Type $\mathrm{V}$ can stem from Type IV lesions with lipid deposits (Type Va) with additional fibrous tissue or multilayered fibrous tissue with multilayered lipid deposits. Type $V$ can also have calcium deposits (type $\mathrm{Vb}$ ) or no lipid or calcium deposits (type $\mathrm{Vc}$ ) (Stary et al. 1995b). Unlike type IV lesions, type V lesions occlude the artery slowly leading to gradual complications.

The characteristics of type VI the lesion include fissure, hematoma, and thrombus. Type VI additionally can have the lipid characteristics of type IV or the calcium and/or fibrous tissue characteristics of type V. Fissures, which are tears or grooves in the surface of a lesion, can cause hematoma and thrombosis. In extreme cases they can structurally weaken the artery. Fissures vary in size and length; consequently the effect of fissures varies. Thrombosis, which is also a 
characteristic of Type VI lesions, also varies in degrees of seriousness. Thrombi due to denudation and erosion on the endothelial surface, in which smaller arteries are prone, can accumulate in size over months and years. Another source of thrombi can be due to a disruption or tear in the cap of lipid-rich plaque commonly known as plaque rupture. According to Stary et al. (1995b), aneurysm can also happen due to type IV, V and VI but happen most frequently due to type VI lesions with highly eroded intimal surfaces. This causes the fibrous matrix to degrade and the aneurysm to form. Lesions can come in a wide variety of shapes, sizes, characteristics, and risks. This makes quantifying the risk of a lesion difficult.

Stary et al.'s articles have been criticized by scholars due to the implication that by numbering differing stages of lesions, the severity of the lesion would increase with an increase in the numbering system (1995a,b). However this is not necessarily true. For example, Type IV is more often more dangerous than type VI. Thin cap atheromas are characterized by a lipid deposit covered with a thin layer of fibrous tissue. According to Stary et al.'s definition, this would be a type IV lesion(1995b). Any lesion regardless of its lipid content or stenosis with fissure, hematoma, or thrombus is classified as type VI. Type VI lesions aren't necessarily as risky as type IV lesions since type IV can also result in sudden cardiac arrest if rupture occurs (Stary et al. 1995b).

Virmani et al. (2000) finds Stary's AHA classification system cumbersome and incomplete when dealing with varying issues of atherosclerosis issues. The system is difficult for users in that first, it uses a very long list of roman numerals 
that is difficult to remember. Secondly, it implies a linear progression when arteries can progress in multiple ways (Virmani et al. 2000).

Virmani et al. (2000) proposes a new classification system that is consistent with the AHA but is more user friendly and descriptive. Virmani et al. (2000) argues that the AHA does not address two factors associated with sudden coronary death: First, death without occlusion, such as due to a fatal arrhythmia, is omitted. Second, the relationship of luminal narrowing to other features of plaque progression is not addressed.

The classification system is broken into six categories. Intimal xanthoma replaces the term "fatty streak" or "initial lesion" in the AHA scheme. "“Xanthoma" is a general pathological term that describes focal accumulations of fat-laden macrophages". These lesions in animal models are very different than human. Human lesions are able to regress while animal ones can not.

The next category Intimal thickening originates from preexisting intimal masses. Intimal thickenings have overlying regions of thrombosis and an erosion or absence of an endothelium that can cause thrombus over an extended period of time.

Virmani et al. (2000) defines Fibrous Cap Atheroma as a distinctive layer of connective tissue completely covering the lipid core. Fibrous Caps consist completely of smooth muscle cells in a collagenous proteoglycan matrix. "Fibrous Cap" encompass both types IV and V in the AHA system. The difference between the two is the degree of the cap formation, the extent of the lipid core, and the development of complicating features. 
Thin Fibrous Cap Atheroma is not included on the AHA chart. While Type IV lesions can be included in this categorization, these lesions are vulnerable to rupture and therefore highly risky. A thin cap is defined as $<65$ micrometers from the lumen of the artery to the nearest lipid pool. Additionally these lesions are defined by loss of smooth muscle cells, extracellular matrix, and inflammatory infiltrate. Necrotic core underneath is usually large. Hemorrhage within the arterial wall and calcium may be present. Studies have found that $60 \%$ of acute thrombi were a result of thin fibrous cap atheroma. While thin fibrous caps are highly risky, they do not always rupture and are not always the main cause of stroke, infarct, or death.

Calcified Nodule is a straightforward category which refers to lesions with thrombi due to extensive calcium nodules. Since calcium is easily seen under fluoroscopy, physicians use calcium imaging as one indication of disease state. However, this is only one factor in a complicated disease.

The final category, Fibrocalcific Plaque contains calcium nodules and fibrous tissue. Fibrocalcific plaque does not contain a thin cap and is not prone to rupture or thrombus (Virmani et al. 2000). However, these lesions can lead to a narrowing of the lumen. This type of stenosis can be difficult to reopen using angioplasty or stents due to the rigidity of the artery.

Like Virmani et al. (2000), Naghavi et al. (2003) also classifies arteries by characteristics of the plaque rather than a number or letter classification. Since the disease states do not necessarily follow a linear progression, characterizing the plaque by feature is more sensible. 


\section{Other Factors that Affect Atherosclerosis}

Naghavi et al. (2003) introduces the term "vulnerable patient". This includes patients with all types of plaque that can either rupture, cause thrombosis, or have vulnerable myocardium, meaning the tissue is prone to fatal arrhythmia. Sudden cardiac arrest can happen without thrombosis. This can be from an eroded endothelial lining of the artery, from improper electrical conduction, or from previous injury resulting in myocardial damage (Naghavi et al. 2003). They deduct that the terminology "vulnerable blood" and "vulnerable myocardium" are also relevant in describing atherosclerotic risks. The term "cardiovascular vulnerable patient" is proposed to define subjects susceptible to an acute coronary syndrome or sudden cardiac death based on plaque, blood, or myocardial vulnerability. Currently there is no way of quantifying patient risk to predict cardiac events such as plaque rupture, arterial occlusion, stroke, and heart attack (Naghavi et al. 2003).

Naghavi et al. (2003) calls for the development of a quantitative classification system to identify both the characteristics and the risk of disease state. The variables would be based on a combination of plaque vulnerability, blood vulnerability, and myocardial vulnerability. Naghavi et al. (2003) proposes the following as the major criteria for defining vulnerable plaque includes:

- Active inflammation (monocyte/macrophage and sometimes T-cell infiltration) 
- Thin cap with large lipid core

- Endothelial denudation with superficial platelet aggregation

- Fissured plaque

- Stenosis $>90 \%$

The minor criteria for defining vulnerable plaque includes:

- Superficial calcified nodule

- Glistening yellow (based on cadaver dissection)

- Intraplaque hemorrhage

- Endothelial dysfunction

- Outward (positive) remodeling

Maseri and Fuster (2003) agree with Naghavi et al. (2003) that there are distinguishing features which distinguish high risk plaque from other plaque. These risky features include complex coronary stenosis, coronary plaque fissures, fresh thrombi, and plaque inflammation.

\section{Plaque Rupture: Mechanisms and Thrombi}

Whether plaque is "vulnerable", "high risk", or "culprit", the fact remains that the factors which affect plaque progression are not completely understood. Factors include stress, diet, smoking, blood pressure, among others. Due to the high mortality rate caused by plaque rupture, much research has gone into understanding the mechanisms surrounding rupture. $60 \%$ of myocardial infarction is caused by the rupture of vulnerable plaque. $95 \%$ of cardiac arrest patients die before they reach the hospital (Tang et al. 2005). If high-risk plaque can be identified before rupture, cardiac arrest due to myocardial infarction may be prevented.

"Atheroma" historically refers to a dermal cyst. The plaque caused from thin cap atheromas rupture can be seen as analogous to the capsule containing 
an abscess. Plaque ruptures similarly. Like a blister, plaque can burst due to areas of high stress. When a lipid pool burst, the lipid, tissue factor, and collagen fibrils meet the blood stream. The blood coagulates and a thrombus is quickly formed (Davies 1996). Thrombi are composed mostly of platelets and/or fibrin (Maseri and Fuster 2003). A cascade reaction caused by cap rupture can lead to total occlusion. Thin cap atheromas are defined as having a lipid core which is greater than $40 \%$ of the total lesion area and a cap thickness of 65 to 150 micrometers. The fibrous tissue is weak due to the inflammatory response on the collagen structure and therefore susceptible to mechanical stress. Plaque may become unstable over weeks, months, or years. Stress on the artery wall can be related to blood pressure, vessel and plaque geometry, vessel thickness, and lumen area, plaque structure, material properties of the vessel and plaque components, flow wall shear stress, and axial pre-stretch and residual stresses (Maseri and Fuster 2003). Much like a blister, lipid pools can rupture due to high stress. In a study by Cheng et al. (1993), arteries of patients who died of acute plaque rupture were inspected for peak circumferential stresses. From the 12 lesions inspected, 31 areas of high stress regions were found. Most rupture occurred in areas of high stress. This implies that areas of circumferential stresses in lesions are the cause of rupture. A study by Loree et al. (1992) found that plaque did not rupture in highest stress area but in the second or third highest area. Plaque rupture is difficult to predict.

Blood pressure is non-uniform and becomes especially complicated in severely stenosed arteries. Pressure is lower at the narrowest part of the lumen 
implying that the highest stresses are actually in a healthier part of the artery. However if the stenosis has a thin cap and large lipid pool, maximum stress can be observed. Tang et al. (2005) continues, "The relationship between maximal stress and plaque rupture is really not as well established as commonly believed."

According to Cassells et al. (2008), thrombosis is not always dangerous; thrombosis is only dangerous if it embolizes which is difficult to predict. If embolization and lysis is incomplete and followed by re-endothelialization, the result is plaque growth. Rapid plaque growth can also happen through hemorrhage into plaque. Other plaques form foci because of rapidly growing smooth muscle cells (Cascells et al. 2008). The many sources of thrombi and the unpredictability of embolization make risk difficult to evaluate.

Thrombus is not only due to plaque rupture - endothelial denudation can also be a source. Thrombi can be composed of many layers over an extended time period. This suggests that a weak thrombogenic stimuli causes thrombi over a long time period. High risk blood could be involved with non-lipid-rich but highrisk plaques (Maseri and Fuster 2003). In the study by Virmani et al. (2000) found that $35 \%$ of the lesions in their study with thrombus did not show rupture and showed little inflammation. Therefore thrombi can form without rupture (Virmani et al. 2000).

Virmani et al. (2000) separates occlusion into two categories: fresh occlusion and old occlusion. Fresh occlusion is identified by its pathological composition of platelet aggregates with inflammatory cells and red blood cells. 
The new occlusion is dominated by fibrin and contains red blood cells and leukocytes. Little or no endothelial or smooth muscle cells are present. Old occlusions are characterized by dense collagen and proteoglycan, smooth muscle cells, and inflammatory cells. They may also include the characteristics of fresh occlusion (Virmani et al. 2000). The comparative risks of fresh occlusion compared to old occlusion have not been evaluated.

As mentioned in the Stary et al. (1995a,b) classifications, another significant feature found in post-mortem studies is fissure. Fissure is a groove in the artery. Fissures are risky because they lack endothelial cells and if a groove forms deep enough rupture can occur. Maseri and Fuster (2003) noted that fissure can be considered a high risk type of disease state even without inflammation or lipid pool. Fissures provide weak thrombogenic stimuli over a long period of time which develop thrombi in the same manner as endothelial denudation.

Calcium is a common component in diseased arteries. While calcium certainly stiffens arteries, whether calcium stabilizes or destabilizes the artery is open to debate. Calcium is common in atherosclerosis but the reasons why calcium builds and the impact of calcium are not well understood (Li et al. 2007). Also the correlation between calcium and lipid pool is not understood. Calcium has the potential to either lower stress or increase stress. This may either prevent plaque rupture or cause plaque rupture.

While stenosis does increase the chance of hemolysis and can flag symptoms associated with atherosclerosis, stenosis does not always increase 
the risk of plaque rupture. Even though some pathologists equate stenosis with high-risk plaque, this is not always true. "Cross-sectional luminal narrowing of $>75 \%$ is not a prerequisite for luminal thrombosis, either acute or healed, or for the development of intraplaque hemorrhage"(Virmani et al. 2000). More than $50 \%$ of the thrombi found in the excised arteries in the study by Virmani et al. (2000) occurred at lesion sites with less than $75 \%$ cross-sectional area stenosis by plaque. This implies that repeated ruptures may be responsible for plaque progression. Arteries are not compromised when the artery restructures itself to allow plaque growth by expanding the outer diameter rather than the inner diameter (Virmani et al. 2000). Naghavi et al. 2003 agrees that nonstenotic plaque is more common than stenotic plaque. Non-stenostic plaque is the cause of the majority of ruptured plaques. Maseri and Fuster (2003) explain that complex stenosed plaques can undergo remodeling and become smooth or become complex and be functionally stable. The variety of atherosclerotic plaque characteristics makes scaling risk factors a daunting task.

\section{Demand and Complexities in Standardizing Vulnerable Plaque Risk}

In order for vulnerable plaque risk to be standardized, much investigation needs to occur into the mechanisms of plaque ruptures and causes thrombi. The complexity of the cardiac system makes this no easy challenge. Maseri and Fuster (2003) wrote that the triggers of rupture are "multiple and complex, structurally and functionally". By evaluating individual components of atherosclerosis a larger picture can be developed with time. This paper will evaluate whether Stary et al.'s (1995b) type IV lesion or Virmani et al.'s (2000) 
thin cap atheroma is stabilized with the presence of calcium. By using (FEA) finite element analysis, the level of stress with varying levels of $\mathrm{Ca}+/ \mathrm{Lipid}$ percentage can be evaluated. By comparing a model of a lipid with calcium to the same area of lipid without calcium, the net effect of calcium behind the lipid pool can be examined.

\section{CHAPTER 2: LITERATURE REVIEW}

\section{Finite Element Analysis (FEA) and Atherolsclerosis:}

Researchers have applied computer simulations to learn more about atherosclerosis since 1989 when Richardson et al. (1989) used the histology of ruptured arteries to create a finite element model (FEM) to solve for stress. Rupture tended to occur at areas of high circumferential stress. Since then many other researchers since then have used FEA as a tool to examine atherosclerotic states. Models are either based on the geometric histology of a cadaver artery or an idealized arterial geometry. Models can either be 2D or 3D. Models also can simulate differing materials including the arterial wall, lipid pools, fibrous tissue, thin cap atheroma, and sometimes calcification.

Many researchers have focused using FEA to model specifically stress on thin cap atheromas. Richardson et al. (1989), Loree et al. (1992), Cheng et al. (1993), Baldewsing et al. (2004), Finet et al. (2004), and Li et al. (2006b) studied lipid deposits with thin fibrous caps using FEA. Their work has focused on high stress concentrated areas, the effect of cap thickness, the effect of size of lipid pools, material properties of arterial tissue, and the difference between 
histological models compared to ideological models. The following articles have used FEA as a tool to explore atherosclerosis.

In 1989 Richardson et al. pioneered applying finite element analysis to atherosclerotic plaque. The researchers examined plaques from 85 patients who had died from coronary thrombosis. $67 \%$ of the examined plaque contained lipid pools and $63 \%$ of the examined plaque had fissure at the cap. Using a computer simulation, the researchers found areas of high circumferential tensile stress were concentrated on the plaque cap especially near the edge of the plaque. The ruptures generally occurred close to high stress. Additionally foam cells were discovered at the site of the tear. They concluded the weakening of the cap could be due to foam cells in situations when the tear was not at the point of maximum stress.

Instead of using the geometries of cadaver arteries, Loree et al. (1992) examined the peak circumferential stress of atherosclerotic lesions using the cross sections of ten idealized arteries with varying fibrous caps thicknesses, lipid pools and stenosis percentages. An idealized model can be advantageous in that the parameters are simplified allowing only one variable parameter. A general trend within the variable parameter can then be concluded. A constant luminal internal pressure of $100 \mathrm{~mm} \mathrm{Hg}$ was applied. A diameter of $2.0 \mathrm{~mm}$ outer radius and 1.8 $\mathrm{mm}$ inner diameter was used. This is less than half as large as a normal coronary artery. The severity of the stenosis varied from $70 \%$ to $99 \%$. The fibrous cap varied from $.05 \mathrm{~mm}$ to $.50 \mathrm{~mm}$. The lipid pool varied from $19 \%$ to $54 \%$. Three tests were performed with no lipid pool in which the stenosis varied at values of 
$70 \%$ to extreme stenosis of $94 \%$ and $99 \%$. Linear elastic properties were used. The values of elasticity were transversely isotropic so that the circumferential $(\theta)$ direction and axial $(z)$ direction had similar properties while the radial $(r)$ direction differed in properties. A fibrous cap of 50 microns with a stenosis of $70 \%$ resulted in a stress of $363.7 \mathrm{kPa}$. A fibrous cap of 150 microns and a stenosis of $70 \%$ resulted in a stress of $134.9 \mathrm{kPa}$. The results of lowering the cap thickness are dramatic increases in stress. Reducing the fibrous cap by $66 \%$ resulted in an increase in stress of $267 \%$. A sensitivity analysis was also performed to determine if the amount variation in their parameters effected the models they used. Changes in the elastic modulus in the plaque region had a sizeable effect. Changing the Poisson's ratio and shear modulus within plaque had little effect on the outcome of stress. Changing the elasticity and shear modulus within the artery had very little effect on the change in stresses.

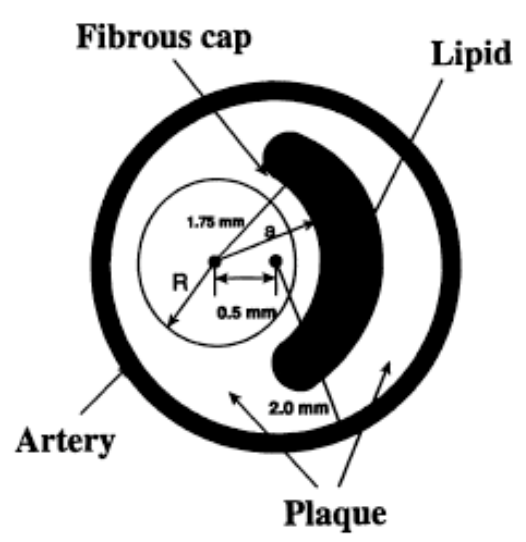

Figure 1. Geometry used for Loree et al. The FEM is Composed of Fibrous Cap, Lipid, Plaque, and Artery.

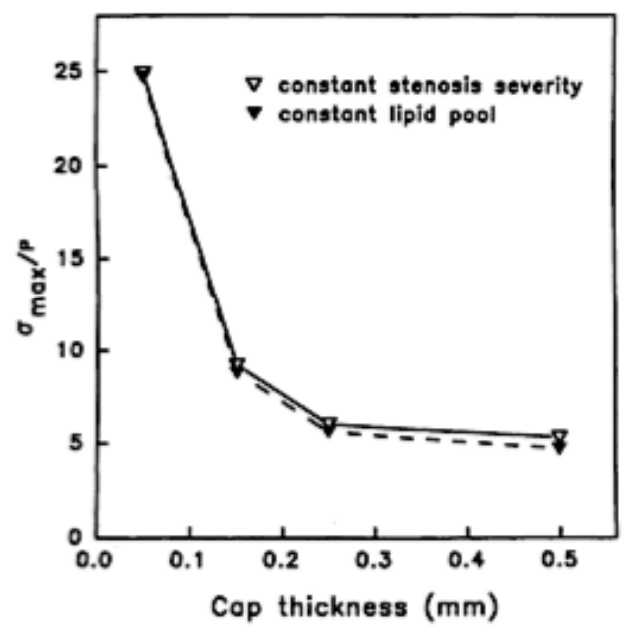

Figure 2. The Stress on the Fibrous Cap as a Function of Cap Thickness. 
In 1993 Cheng et al. concedes that atherosclerotic plaque is the cause of most acute coronary syndromes, the mechanics and dynamics plaque rupture still remains uncertain. They hypothesized that plaque rupture occurs at sites of high circumferential stress in the artery. To test this theory, 12 coronary arteries with stable control lesions were compared to 12 vessels with lesions in which caused a myocardial infarction. Finite element models were created to test the stresses in each vessel. A mean pressure of $110 \mathrm{mmHg}(14.7 \mathrm{kPa})$ was used. The material properties were modeled as transversely isotropic.

Table 1. Material Parameters for Plaque and Artery Used in Finite Element Models for Cheng et al. 1993

\begin{tabular}{|c|c|c|}
\hline Parameter & Plaque & Artery \\
\hline $\mathrm{E}_{\mathrm{r}}(\mathrm{kPa})$ & so & 10 \\
\hline $\mathrm{E}_{\boldsymbol{g}}(\mathrm{kPa})$ & 1,000 & 100 \\
\hline $\mathrm{G}_{\text {us }}(\mathrm{kPa})$ & 500 & so \\
\hline$\nu_{10}$ & 0.01 & 0.01 \\
\hline$v_{t x}$ & 0.27 & 0.27 \\
\hline
\end{tabular}

The Poisson's ratio used was 0.27 . FEMs were created using ABAQUS software. Huang et al. (2008) notes that the stress point at rupture is around $300 \mathrm{kPa}(2,250 \mathrm{mmHg})$. The maximum stress in the plaques that ruptured was much higher than in the stable lesions. In the twelve fatal lesions, 31 areas of high stress (over $300 \mathrm{kPa}$ ) were found whereas only one unstable area was found. The average stress for the ruptured lesions was around $545 \mathrm{kPa}$. The average stress for the stable lesions was magnitudes less - around $193 \mathrm{kPa}$. One important finding that Cheng et al. (1993) found was that plaque does not rupture at the areas of highest stress every time. Many times, the areas of second or 
third highest stress ruptured. The study concluded that local variations in plaque material properties contribute to plaque rupture.

Baldewsing et al. (2004) compared a FEM from five excised human arteries to the actual elastograms obtained from the models to validate the FEMs accuracy in simulating strain behavior. Eight areas of high strain regions (HStR) were found in the five arteries. The arteries were obtained from patients who died of non-coronary causes but had a fair amount of lipid, thin caps, and eccentric heterogenous plaque. The measured elastograms were processed from radiofrequencey data using Intravascular US (IVUS) elastography. This machine is clinically available for either in vitro or in vivo analysis. IVUS can be used to find mechanical and morphological information about plaques. Previously the IVUS was used in the first portion of a study by Veress et al. (2000) to find the creep and quasistatic stress/strain responses of porcine coronary arteries.

Table 2. Material Parameters for Plaque and Artery Used in Finite Element Analysis for Baldewsing et al.

\begin{tabular}{|l|c|}
\hline Material & Young's Modulus (kPa) \\
\hline Lipid: & 50 \\
\hline Smooth Muscle Cell(SMC): & 1000 \\
\hline Collagen: & 1500 \\
\hline Lipid + Macrophage: & 25 \\
\hline SMC + Macrophage: & 500 \\
\hline Collagen + Macrophage: & 750 \\
\hline SMC + Lipid: & 500 \\
\hline Collagen + Lipid: & 750 \\
\hline SMC + Collagen: & 1250 \\
\hline
\end{tabular}

The FEA was done using Sepran software. The geometry was obtained using a custom-written graphic user interface developed using MATLAB. The material properties of the arterial tissue was set to be linear elastic, isotropic, 
nearly incompressible, and plane-strain material. A Poisson's ratio of 0.4999 was used. The Young's modulus (in $\mathrm{kPa}$ ), based on previous studies, for the nine differing materials were:

Strain was then obtained for the different arteries. Strain for the arteries varied anywhere from 1.15 to 1.79 for the FEM. This was within and average of $.03 \%$ compared to the actual strain. Statistical analysis found that there is no significant difference between the actual and the simulated data. They concluded that using FEM from a measured elastogram is a helpful way of characterizing strain-dependencies which can help to reconstruct a model with accurate Young's modulus. While this study did not focus on rupture values, the research into past studies compared to actual values for strain and Young's modulus is very helpful for future research. Using the IVUS elastography technology, plaque rupture risk in the future may be predicted.

To test whether thin fibrous cap is the defining characteristic of vulnerable plaque, in 2004 Finet et al. tested computational models that included a thin fibrous cap. Six idealized models were created based on three images of typical ultrasound of fibrous cap atheroma. The fibrous cap was decreased (values of $230,205,118,70,32$ and 15 micrometers), the Young's modulus of the lipid core was varied, and the models were tested at eight different physiological loading blood pressures. This totaled to 414 simulations. The material properties were modeled as transversely isotropic. Linear elastic properties were the same in the circumferential and $z$ directions and different in the radial direction. The material values for Young's modulus, Poisson's ratio, and strain were close to that of 
Cheng et al.. The lipid cores properties were varied from a rang of $5 \mathrm{kPa}$ to 400 $\mathrm{kPa}$. FEA was performed using ANSYS 5.7 software. Blood pressures ranged from $6,8,10,12,14,16,18$, and $20 \mathrm{kPa}$.

Increasing blood pressure on the cap had a linear effect. If the pressure was doubled the peak stress was doubled. The effect of decreasing the fibrous cap had an exponential effect of increasing the peak stress. Cap stresses were around $250 \mathrm{kPa}$ when the cap was 70 microns. Increasing the Elastic modulus of the lipid core reduced the stress. Increasing the lipid core material properties from $1 \mathrm{kPa}$ to a soft atheromatous value of $400 \mathrm{kPa}$ reduces the stress from values that lie above the rupture point of $300 \mathrm{kPa}$ to that below the rupture value. Composition has a substantial effect on the stress values. Finet et al. concludes that blood pressure, cap thickness, and material composition all play an

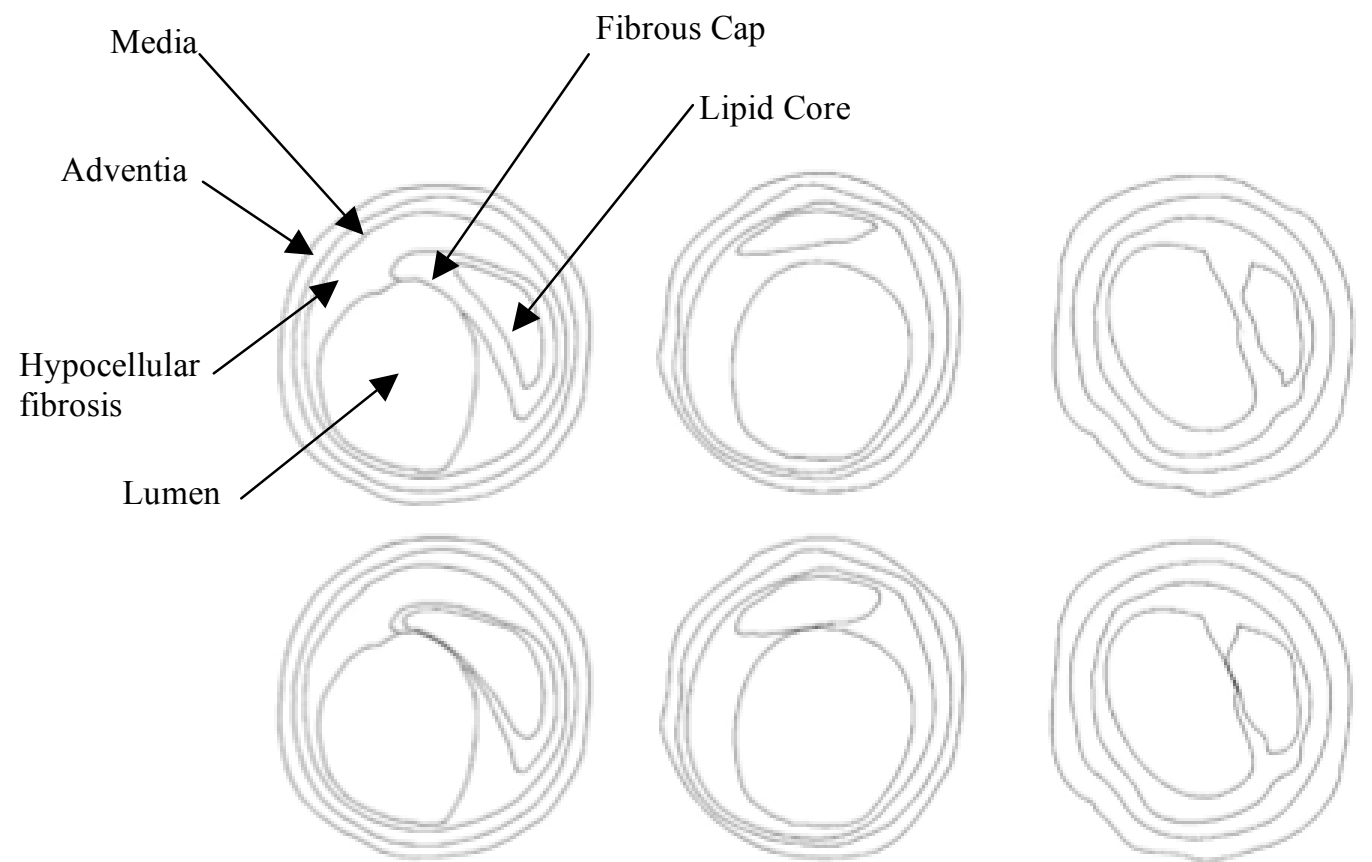

Figure 3. The six idealized MRI models from Cheng et al. (1993). Images of One fibrous-cap fibro-atheromatous plaque (plaque 1 , cap thickness $=230$ microns) and two thin-cap fibroatheromatous plaques (plaques 2 and 3, cap thicknesses $=36$ and 53 microns) Six idealized models in whch the fibrous cap decreases from 230 to 15 micros were manually traced by increasing the initial lipid core size for each plaque. 
important role in plaque rupture (20040. In order to predict rupture through imaging techniques, all three factors must be accounted. To further test these factors, truly idealized models should be tested so that irregular geometries do not skew the results.

Li et al. (2006b), in the article How Critical Is Fibrous Cap Thickness to Carotid Plaque Stability? Flow-Plaque Interaction Model, used idealized models to measure thin cap stresses. The team used a coupled nonlinear timedependent model with a flow-plaque interaction simulation and stress/strain analysis in a stenotic carotid artery model. Stress was calculated by varying the cap thicknesses, ranging from $.100 \mathrm{~mm}$ to $2 \mathrm{~mm}$, and varying the degree of luminal stenosis, ranging $10 \%$ to $95 \%$.

Instead of using linear elasticity, Li used the Ogden parameters:

Table 3. Ogden Material Parameters for Plaque and Artery in the Finite Element Model for Li et al. (2006b).

\begin{tabular}{lccccc} 
Tisue propertics & $\mu_{i}{ }^{*}$ & $\mu_{z}{ }^{*}$ & $\alpha_{i}{ }^{+}$ & $\alpha_{z}{ }^{+}$ & $K\left(M P_{n}\right)^{*}$ \\
\hline Vessel wall & 0.0008 & -0.0008 & 30 & -30 & 1600 \\
Fibroes cap & 0.0015 & $-0,0015$ & 30 & -30 & 3000 \\
Lipid pool & 0.0001 & -0.0001 & 27 & -27 & 200 \\
\hline
\end{tabular}

The Ogden Equation:

$$
W=\sum_{i=1}^{N} \frac{\mu_{i}}{\alpha_{i}} J^{-\frac{\alpha_{i}}{z}}\left(\lambda_{1}^{i}+\lambda_{2}^{j}+\lambda_{z}^{z^{i}}-3\right)+4.5\left(K^{-\frac{1}{z}}-1\right)^{2}
$$

$\mathrm{N}$ is the number of terms (2 used in this simulation), $\lambda_{i}$ are the principle stretch ratios, $J$ is the Jacobian modulus, $K$ is the bulk modulus; $\mu_{\mathrm{i}}$ are moduli constants and $\mu_{1}=\mu_{2}, l$ and are $\alpha_{i}$ exponent constants and $\alpha_{1}=\alpha_{2}$. 


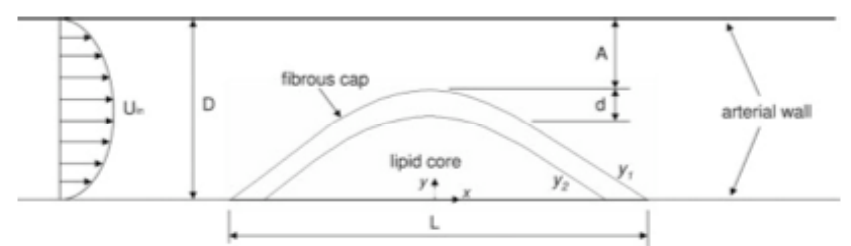

Figure 4: Geometry used for Li et al. (2006b). In the model, $D=10 \mathrm{~mm}, \mathrm{~L}=20 \mathrm{~mm}, \mathrm{~d}=$ the fibrous cap thickness, $A=$ lumen diameter in the maximal diseased part of the vessel.

As expected, Li et al. (2006b) found as the cap becomes thinner and the stenosis becomes greater, the peak stresses increase. The results indicate that when the cap falls below 200 microns, the artery is at risk of rupture at only $40 \%$ stenosis. Current practices don't operate on stenosed arteries until they reach $70 \%$.

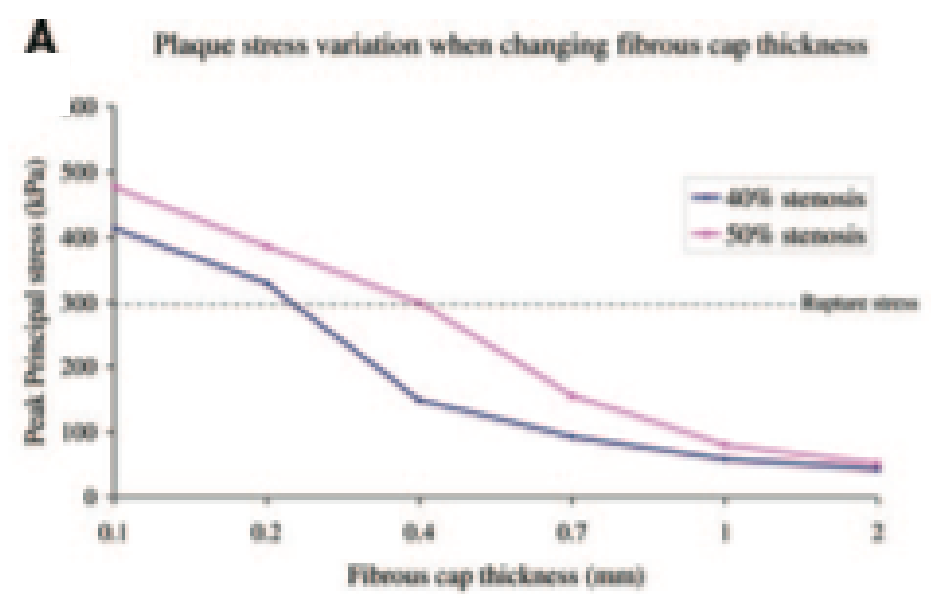

Figure 5. Plaque stress variation within $40 \%$ and $50 \%$ stenotic arteries as a function of fibrous cap thickness.

Plaque stress reached as high as $700 \mathrm{kPa}$, over double the expected rupture value. The maximum stress occurred at the highest degree of stenosis (95\%) with the thinnest cap. This data disagrees with Tang et al. (2004) which found stress decreased in severe stenosis. The high stress results could be due to the fact that the cap was not nearly as thin as Li et al.'s model (2006b). This 
suggests that a 3D model could be important in clarifying the extent stenosis plays for maximum stresses on thin cap atheroma.

Li et al. (2006b) also tested how shape affects stress - specifically how the eccentricity of the lesions affected the stress concentration. By keeping all factors constant except eccentricity, eccentricities of 30-30, 20-40, 10-50, and 0-60 were tested. The stresses ranged from $155.33 \mathrm{kPa}$ at $30-30$ to a maximum of 169.32 $\mathrm{kPa}$ at $0-60$. This suggests that plaque eccentricity doesn't have a major role in plaque rupture.

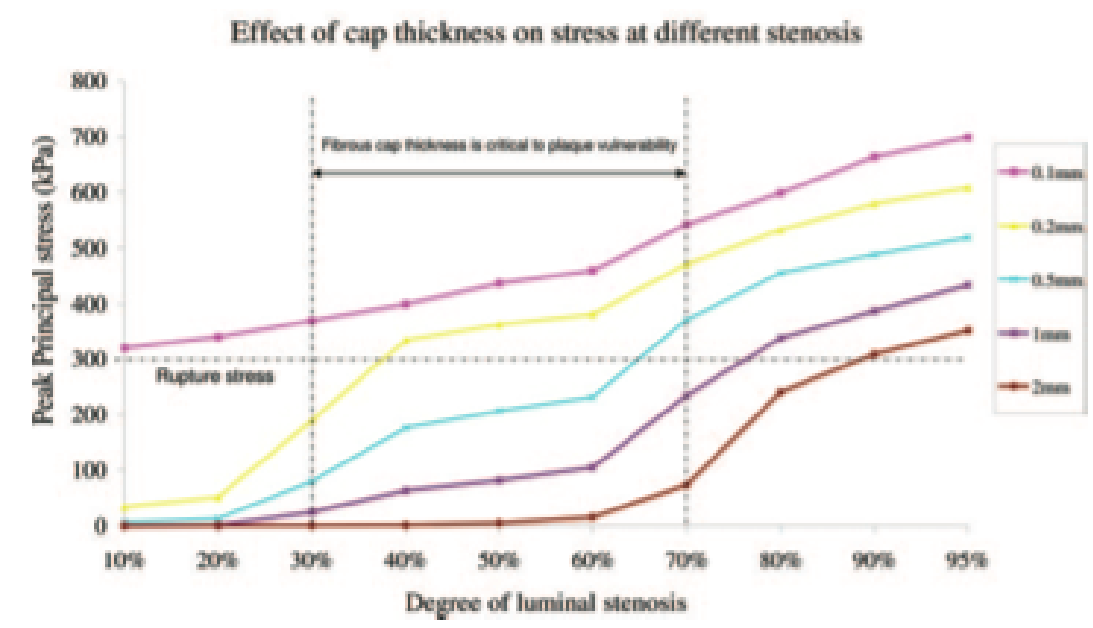

Figure 6. Effect of the fibrous cap thickness on plaque stress at different degrees of luminal stenosis. Plaque fibrous cap thickness is critical to plaque vulnerability when the luminal stenosis is between $30 \%$ and $70 \%$ (rupture stress was taken to be $300 \mathrm{kPa}$ ).

\section{Calcification and FEA}

Although the mechanisms of calcification formation are still not certain, the drastic difference in material properties between lipid deposits and calcification have raised concern for studying the effect of calcium and lipid rupture. Many researchers have included calcium in their FEM (Lee 2000, Huang et al. 2001, Tang et al. 2005, Veress et al. 2000 and Li et al. 2005, 2007b). The following 
articles can be examined to find a clearer picture of the effect of calcium on rupture stresses. A key question is whether calcium increases the stress on a lipid pool or helps lower the stress and stabilize and artery.

In 2000 R. T. Lee tested arteries for their material properties. Arteries have differing properties in the "normal" and the "circumferential" direction the lesions were placed under compression in the "normal" direction and the lesions were placed under tension in the "circumferential" direction. They found that the stiffness was related to the composition of the artery. Calcification drastically increased the stiffness approximately tenfold compared to cellular tissue. Fibrous tissue was about twice as stiff as cellular lesions. The circumferential stiffness found under tension is approximately 100 times grater than radial stiffness. Lipids were assumed to be magnitudes less stiff than fibrous tissue.

In defining the properties for the finite element analysis, the tissue was considered to be "transversely isotropic." The same properties were used in the circumferential and axial directions while the radial direction had different properties. To describe the material properties, five parameters are needed: two elastic moduli, two Poisson's ratios, and one shear modulus.

Lee tested arteries to determine their mechanical properties (2000). "Our data suggest that peak stresses in the atherosclerotic lesion are particularly sensitive to the elastic moduli, but the shear moduli and Poisson's ratios appear to be less important in determining maximum stress"(Lee 2000).

Lee found that inflammation can lead to rapid degradation of the cellular matrix (2000). Since inflammation is difficult to image, methods need to be 
developed to identify inflammation in vivo. The effect of calcium also decreases the overall strength in the lesion because microfractures can compile, leading to a complete failure of the artery. However, it is difficult to make a general rule about how calcium effects lesion stability. "In some cases, extensive calcification can lead to a marked decrease in stress in the fibrous cap, so that even in the presence of large underlying lipid pool, the extensive calcification leads to an increase in stability of the lesion"(Lee 2000). On the other hand, calcium can lead to increased stress around the shoulder region. Lee (2000) concluded that calcium can have a positive or negative influence on lesion stability. "We will need to understand much more about the natural history of calcification as well as the role of calcification in plaque rupture to distinguish these two possibilities" (Lee 2000).

A report by Huang et al. (2008) studied the difference in maximum principle stresses between ruptured and stable lesions. This study's objective was to describe the difference between fibrous and non-fibrous materials. A histological cross-section of arteries were studied to form an ideal model that mimicked the in vivo geometry. The anatomy of the artery was simplified to fibrous plaque, lipid deposits, and calcification. Fibrous deposits were defined as any plaque that was non-lipid and non-calcified. Then using FEA, the calcified lesions were replaced with fibrous lesions to "compare the relative impacts of calcification and lipids" (Huang 2008). The study used the geometries of 10 ruptured and 10 stable coronary arteries. 
Table 4. Mooney Rivlin Constants Used in Huang et al. 2008.

\begin{tabular}{|l|l|}
\hline \multicolumn{2}{|l|}{ Mooney-Rivlin constants: } \\
\hline Arterial Wall: & D1 $=2644.7 \mathrm{~Pa}$ \\
& $\mathrm{D} 2=8.365$ \\
\hline Lipid: & $\mathrm{D} 1=50 \mathrm{~Pa}$ \\
& $\mathrm{D} 2=.5$ \\
\hline Fibrous Cap: & $\mathrm{D} 1=5105.3 \mathrm{~Pa}$ \\
& $\mathrm{D} 2=13$ \\
\hline Calcium & $\mathrm{D} 1=18808.5 \mathrm{~Pa}$ \\
& $\mathrm{D} 2=20$ \\
\hline
\end{tabular}

\section{Mooney-Rivlin material}

properties were used to imitate the nonlinear elasticity of arterial tissue.

A constant luminal pressure of of

$14.6 \mathrm{kPa}$ was applied. The materials were assumed to be isotropic, incompressible, and uniform. In the

structural analysis, each artery was analyzed three times with differing compositions. First the lesion was digitized. Second, the lesion was modified by replacing the calcification elements with fibrous plaque elements to make a "no calcium" model. Finally the lipid was replaced with fibrous plaque to create a "no lipid model". The maximum peak stress was then recorded for each case.

When the calcified area was replaced with fibrous tissue, the change in max stress increased only by a factor of $0.1 \%$. However, in the stable arteries with large amounts of calcification, the calcium bears large amounts of the load. Therefore, removal of large amounts of calcium would result in a less stable artery.

When the lipid was removed and replaced with fibrous tissue the stress decreased ranging from $5 \%$ to $56 \%$ depending on the geometry of the artery. While Huang et al. concludes that the impact of calcium still remains unclear, lipid pools are a clear signal of instability. Calcium itself may or may not cause instability but can be a marker of disease progression and a flag to other types of disease factors that potentially may be harmful. 
Since the publication of this article, Li et al. in 2007 criticized this study for not using in vivo histological data for the geometry of the artery. Li et al. (2007b) argued that imaging these arteries without the effect of blood pressure to distend the lumen, gives false geometry and therefore the stresses cannot be accurate. Li et al. (2007b) used ideological models in addition to histological models to find a trend and then apply it to a real situation.

Tang et al. (2004) used a 3D MRI based model to find local maximal stress/strain values. A global maximum would certainly be a local maximum. Their model accounted for many variables including a time-dependent 3D flow model, 3D MRI samples of complex geometries with large lipid pools and calcification, variable cap thickness, and variant material strength.

The Navier-Stokes equation was applied for the fluid flow model with the assumptions of laminar flow, Newtonian, viscous, and incompressible material. Tang et al. (2004) also used the Mooney-Rivlin model to describe the plaque as nonlinear, hyperelastic, isotropic, incompressible, and homogeneous. Tang et al. 2004 used their own set of data obtained from research for the values of the Mooney-Rivlin equation which differed from the values used by Huang.

Table 5. Mooney-Rivlin Constants used in Tang et al. 2004

\begin{tabular}{|c|ll|}
\hline Material & Properties & \\
\hline Vessel material: & $c_{1}=9,200 \mathrm{~Pa}$ & $\mathrm{D}_{1}=3,600 \mathrm{~Pa}$ \\
& $c_{2}=0$ & $\mathrm{D}_{2}=2$ \\
\hline Lipid-rich core: & $c_{1}=5000 \mathrm{~Pa}$ & $\mathrm{D}_{1}=5,000 \mathrm{~Pa}$ \\
& $c_{2}=0$ & $\mathrm{D}_{2}=1.5$ \\
\hline Calcification: & $c_{1}=92,000 \mathrm{~Pa}$ & $\mathrm{D}_{1}=36,000 \mathrm{~Pa}$ \\
& $c_{2}=0$ & $\mathrm{D}_{2}=2$ \\
\hline
\end{tabular}

Stenosed plaques excised from cadavers were tested and compared to simulated plaque models to validate the material properties for the FEA models. 
Over 100 computational cases were tested to determine the sensitivity within their values.

The 3D model was obtained from a 3D MRI data set from a human coronary in which 36 slices were used as a standard to develop the computational models. A model was imaged and then manually sliced to identify the components of calcification, lipid rich necrotic core, and fibrotic plaques. By taking 24 slices from a set of 36 samples of cadaveric human coronary plaque sample, then joining each slice to the next, and next smoothing the reconstructed area so that no sharp areas occur, a 3D mesh was constructed. To convert these files APIA is written in Matlab in which the intensities from the MRI were read and an "EDGE" command transferred these into boundaries separating the different groups. If the image had lots of noise, more work was done to adjust the intensity values, lowering the number of artifacts. The imaging sample was compared to the dissected sample "to serve as a benchmark to validate computational findings".

Finite element analysis then was solved using ADINA software. The mesh sizes were adjusted for the varying geometries. Finer mesh was used on thin cap and sharp angles. Pressure in was measured as a variable ranging from 90 to $150 \mathrm{mmHg}$. The stress values of the charts below were measured at maximum pressure of $150 \mathrm{mmHg}$. The chart (c) was also measured using maximum pressure. All eleven cases were simulated at $70 \%$ stenosis, modifying the cap thickness from .02 to $.42 \mathrm{~mm}$. 
High stress/strain variations were found on the models with thin cap. The pulsatile flow seemed to have a large impact of the stress/strain behaviors at these locations. $50 \%$ material stiffness variation of vessel and plaque areas lead to $20-50 \%$ changes in stress maximal level. Interestingly, a more severe the stenosis lead to lower stress levels. Tang et al. (2004) concluded that large-scale patient studies are needed to identify stress/strain risk factors for plaque vulnerability. Although calcium was included in the models, no discussion followed about the effect of calcium. The research focused mainly on the thin cap and locations of peak stresses.
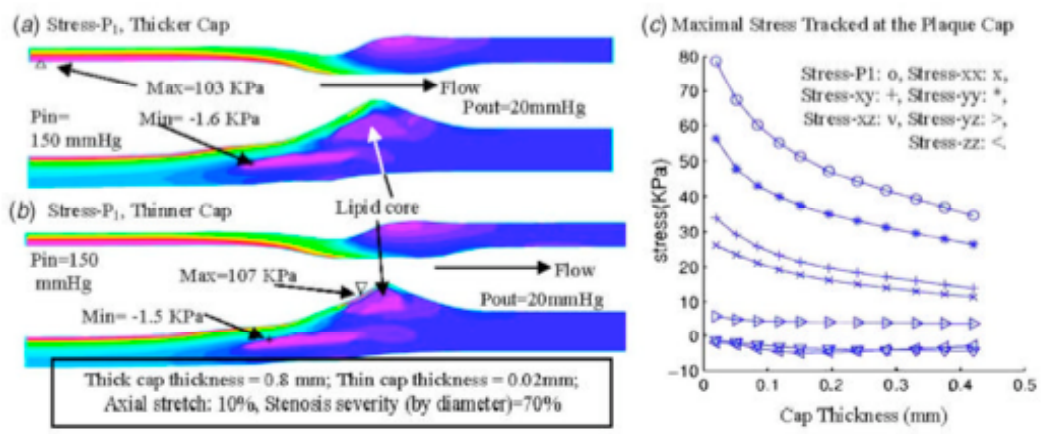

Figure 7a, 7b, 7c. Plaque Stress Levels in Tang et al. (2004). Thinner plaque cap leads to higher stress level: quantitative study. (a) Stress- $P_{1}$ in plaque with thicker cap; (b) maximum of stress- $P_{1}$ appeared at the plaque cap when cap thickness was reduced to $0.02 \mathrm{~mm}$; (c) Maximal value of stress- $P_{1+}$ increases almost exponentially when cap thickness decreases. Eleven cases were simulated using the $70 \%$ modified plaque sample with cap thickness adjusted incrementally from 0.02 to $0.42 \mathrm{~mm}$. $\mathrm{P}_{\text {in }}=150 \mathrm{~mm} \mathrm{Hg}$ are shown.

Veress et al. (2000) used FEA to find changes in plaque stress "as a function of lesion development, and changes in the material properties of lipid pool and plaque cap." While making a linear comparison between age and atherosclerotic plaque state is near impossible, the findings of the study are useful. Geometries were created for the "typical" artery based on age group. Lipid amount increased with an increase in age. The FEM was created and 
tested using Cosmos $^{\mathrm{TM}}$ finite element program. The material properties used were isotropic, linear, and incompressible. The artery was divided into lumen, intima, lipid pool, and arterial wall. In the 30-34 age group (the oldest in the study), cellular cap, calcification, and a stiffer fibrous cap was added. The Poisson's ratio used was .499 . The following values were used for the elastic modulus:

Table 6. Linear Elasticities used in Veress et al. 2000.

\begin{tabular}{|l|l|}
\hline Cellular plaque cap: & $0.51 \mathrm{MPa}$ \\
\hline Fibrous plaque cap: & $0.90 \mathrm{MPa}$ \\
\hline Calcified Plaque cap: & $2.19 \mathrm{MPa}$ \\
\hline Arterial Wall: & $1.74 \mathrm{MPa}$ \\
\hline Lipid Pool: & $0.0174 \mathrm{MPa}$ \\
\hline
\end{tabular}

The maximum stress on the fibrous cap for the 30-34 age group was between $510 \mathrm{kPa}$ to $2,200 \mathrm{kPa}$. Introducing a calcified cap in the $30-34$ model increased the stress by $30 \%$. Veress et al. (2000) hypothesized that calcium near the surface of the plaque would increase the shoulder stress and cause higher stress on the cap itself. Veress et al. (2000) concluded that calcium might play a part in plaque rupture.

In $2005 \mathrm{Li}$ et al. used FEA to test whether calcium increased stresses within a lesion using an idealized model. The study varied the location of the calcium within a lesion with a lipid pool and fibrous cap. The cross section was asymmetrical with $85 \%$ stenosis. The calcium was examined for cases with deposit sizes $\mathrm{A}, 2 \mathrm{~A}$, and $3 \mathrm{~A}$ at each of the five locations. No other geometrical dimensions were given. Two models were tested. First, modified concentric 


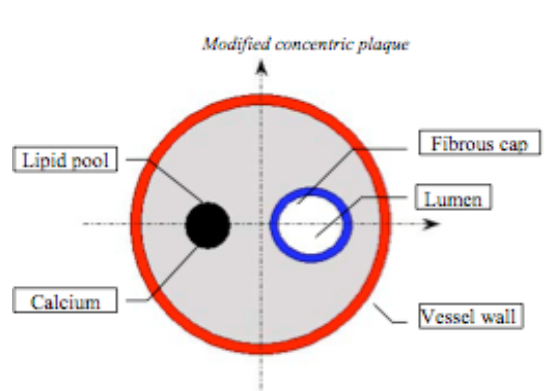

(a)

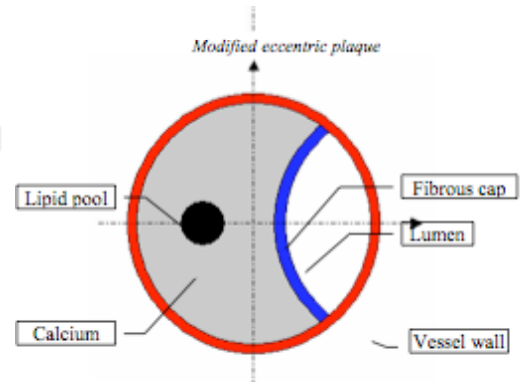

(b)

Figure $8 \mathrm{a}, 8 \mathrm{~b}$. Schematic images of the two different ideal plaque morphologies used in the model in Li et al 2005.

plaque that had fibrous cap surrounding the arterial lumen was tested. Second, eccentric plaque having a fibrous and arterial wall surrounding the lumen was tested. The properties were assumed to be non-linear and incompressible Mooney-Rivlin materials. These properties were obtained from Huang et al. 2001. Numerical analysis was performed using the FEA software ABAQUS.

The calcium was located in five different areas:

1. Calcium deposit in arterial wall

2. In lipid pool close to fibrous cap

3. In lipid pool close to fibrous cap

4. In fibrous cap

5. Fibrous cap on the other side of lumen (in fibrous cap for concentric plaque and in arterial wall in eccentric plaque)

A time dependent pressure wave form was used to mimic the effects of variant pressure during pulsatile flow. Stress and strain were measured using FEA to find the maximum Von Mises stress within the fibrous cap. The calcium deposits were moved in the positions described above. With a hemodynamic flow model, high stress concentration could be seen on the fibrous cap.

The next test studied the effect of location of calcium in respect to the fibrous cap. Von Mises stress increased up to $1.5 \%$ when varying the location of the 
calcium along the lipid pool, distant to fibrous cap. Calcification in the fibrous cap lead to a $43 \%$ increase of Von Mises stress when compared with calcification in the lipid pool. Larger areas of calcification resulted in higher stress values. An increase of $100 \%$ of calcification caused a stress increase of $15 \%$ in the fibrous cap. Calcium position matters.

Eccentric Plaque gave similar results. The stress was slightly greater when the calcium deposit was placed within the fibrous cap than the concentric plaque model. Stress decreased when the calcium deposit was moved to the other side of the lumen but kept within the lumen wall. Calcium deposits within the fibrous cap lead to high stress concentrations in the fibrous cap and may subsequently result in plaque rupture.

Li et al. 2005 concluded that calcium may play a role in plaque ruptures. However, calcium in distant location to the lipid pool does not increase the stress; in fact this may stabilize the plaque. This is consistent with the study by Huang et al.. In the future MRI technology may be able to non-invasively determine the position and extent of calcium deposits to determine the risk of rupture.

Calcium may be a marker to the extent of the disease and risk level for plaque rupture. Inflammation, which is also a risk in plaque rupture, was not accounted for during this study but calcium may be an indicator of inflammation with could indicate plaque denudation and slow forming thrombi. Lee agrees, "because calcification seems to occur in the setting of inflammation, it is possible that calcification appears to be an outstanding marker for future coronary events due to it being an indicator of inflammation". Additionally, Li et al. 2005 notes "the 
material property difference between calcium deposit and fibrous cap may cause crack propagation and lead to material fatigue failure. This suggests that plaque with calcification of the fibrous cap should be classified as vulnerable."

In $2007 \mathrm{Li}$ et al. wrote another paper, Does Calcium Deposition Play a Role in the Stability of Atheroma: Location May Be the Key. This paper used both an idealized and patient-specific model to determine the effect of calcium on the stress distribution. Once again the calcium location was varied in different locations on an idealized model. The next 3 models were derived from in vivo MRI images Li et al. (2007b) criticized other researchers for using in vitro models since the luminal pressure was important in obtaining a correct geometry. The arteries from the MRI images where chosen based on having differing locations of calcification with respect to the lumen and the fibrous cap.

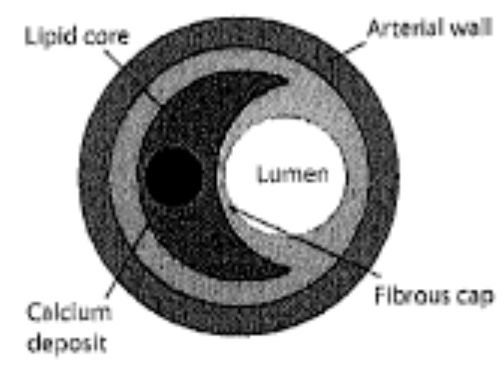

Figure 9. The idealized atheromatous plaque model from Li et al. (2007b). The location of the calcium deposit can be varied. Calcium is shown as the filled black circle.
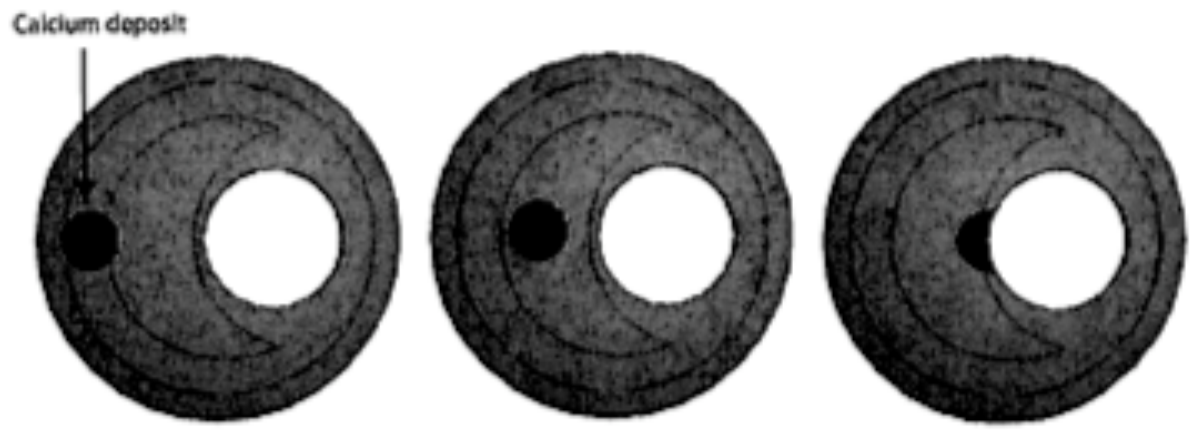

Figure 10. Three Plaques with Varying Calcium Location in Li et al. (2007b). Calcium is marked as the black dot. 
Within the idealized model, calcium deposits were modeled in varying locations and tested for peak stress levels. FEA was performed using ABAQUS software. Li et al. (2007) used a circular vessel wall with a diameter of $10 \mathrm{~mm}$ and a thickness of $1.5 \mathrm{~mm}$. The stenosis was set to $70 \%$. Li et al. had previously used pulsatile flow in simulations. This study used a uniform pressure of $15 \mathrm{kPa}$ $(115 \mathrm{mmHg})$ simulating the mean systolic blood pressure in the carotid artery.

The resulting stresses when the plaque was moved remote from the lumen, in the lipid pool, and in the fibrous cap close to the lumen were 107.5, 103.4 , and $158.6 \mathrm{kPa}$. Calcium within the fibrous cap and close to the lumen created significantly higher stress than the other locations. The patient specific MRI images were captured by imaging axial images of the carotid artery at the point of maximal stenosis. The images were manually delineated, identifying areas of lipid core, fibrous cap, vessel wall, and lumen.

The first patient had no identifiable lipid core. The model was first tested with calcium and next tested with the calcium replaced with fibrous tissue. No significant variation occurred. In the second patient, calcium occurred far away from in the fibrous cap and far away from the lumen, similar to the first idealized model. Once again the model tested with calcium and then the calcium was replaced with fibrous tissue. Again, no significant changes in stress occurred. In the third patient, calcification was located in a thin fibrous cap. Maximum stresses were found to be $331.9 \mathrm{kPa}$ with calcium and $230.7 \mathrm{kPa}$ without calcium - of decreased of $43.9 \%$. Calcification is very dangerous within the fibrous cap position of calcium is significant in determining stress. 


\section{FEA Summary}

Research has found mixed results whether the calcium increases or decreases the stability of a lesion. As Li et al. (2005) has stated in the title of their article, "location may be the key". Many researchers have found that calcium has little impact on stability when located away from the fibrous cap, but greatly increases the stresses on the lesion when located close to or within the fibrous cap. Li et al. (2005) has focused greatly on the effect of calcification on rupture stress using both ideal models and histologically based models. To find the effect of calcium on stress upon the fibrous cap, Li et al. (2005) tested calcium in two differing models, one with a concentric lumen and the other with an eccentric lumen, moving the location of the calcium, to find effect of calcium on the stress upon the fibrous cap. Calcification in the fibrous cap led to a significant $43 \%$ increase of Von Mises stress when compared with calcification in the lipid pool. Huang et al. (2008) also found that calcium had little impact on the stability of lesions when replaced with fibrous tissue. For unstable lesions, when the calcium was replaced, the stress dropped by $26 \%$. Li et al. (2007b) further tested the effect of calcium on lipid pools by comparing an ideological model with calcium in varying locations to a histologically based model. Both models had little variation in stress when calcium was located in areas distant to the fibrous cap; both models' stress was greatly reduced when the calcium was replaced with fibrous tissue. The stress decreased by $43.9 \%$ without calcium. These findings are significant, but the extent of the lipid pool and the extent of calcification is not correlated in any of the articles. R. T. Lee (2000) has a completely different 
opinion in thinking that calcium increases the stability of an artery. It is unclear whether calcification causes additional stress in large lipid pools or if large amounts of calcium impact smaller lipid pools. Further research can be done to further understand the impact of calcium on thin cap atheroma.

As seen in the previous articles, there are many parameters that must be decided upon before building a finite element model. Arterial geometries can either be a 2D transverse cross-section, a 2D longitudinal cross-section, or a 3D model. Also, researchers must decide whether to use an ideal model or a histological model. Histological models can come from imaging cadaver arteries or imaging arteries in vivo. MRI or IVUS techniques are typically used to image. In addition to geometry, material properties must be decided upon. Arterial material properties can be modeled linearly or non-linearly. The Mooney-Rivlin equation and the Ogden parameters have been used by Li et al. in the 2005, 2006(b), and 2007(b) studies. Blood pressure can also be modeled a number of different ways. While applying a constant pressure to the lumen is the most simple way to model pressure, pulsatile models have been developed for flow simulation. Additionally, the amount of pre-stretch and deformation must be determined. Some models have included wall shear stresses. However, Li et al. (2005) noted the shear stresses are insignificant compared to the luminal pressure. Li et al. did not continue to include wall shear stresses in their 2006(b) and 2007(b) studies. Once geometry, material properties, pressure, and deformation is decided upon, a finite element model can be created and tested. 


\section{Chapter 3: METHOD OF INVESTIGATION}

\section{Using FEA to Determine the Interaction of Fibrous Cap Thickness, Lipid Pool Area, and Calcification on Peak Stresses}

Previous studies have determined that there is a relationship between areas of high stress and plaque rupture (Richardson et al. (1989), Loree et al. (1992), Cheng et al. (1993), Veress et al. (2000), and Lee (2000), Huang et al., Baldewsing et al. (2004), Finet et al. (2004), Tang et al. (2005), Li et al. (2005, 2006(b), 2007(b))). Since arterial stresses cannot be directly determined in vivo through any current methods, simulating the stress using computer finite element analysis may allow risk of rupture to be quantified when methods of in vivo material imagining methods are developed.

To find a general trend on the stresses in atherosclerotic lesions due to the effect of calcium on thin cap atheromas, an arterial finite element model (FEM) was created and tested. In the past, researchers have applied a variety of differing material properties to mimic arterial tissue. Some of these include: "hyperelasticity, linear elasticity, material nonlinearity, geometric nonlinearity, piecewise homogeneity, isotropy, transverse isotropy, orthotropy, strain-energy function existence, (near-) incompressibility, initial stress, initial strain, plane stress, plane strain and 3-D" (Baldeswing et al. 2004).

Some researchers have used histological models to find quantify stress values (Richardson et al. (1989), Cheng et al. (1993), Lee (2000), Huang et al. (2008), Finet et al. (2008), Baldewsing et al. (2004), Tang et al. (2005)). Other 
researchers have used idealized models (Loree et al. (1992), Veress et al. (2000), Li et al. (2005, 2006(b), 2007(b))). According to Baldewsing et al. (2004), "a major problem in applying such arterial FEMs for investigation ... is that the majority of those models incorportate arterial features that require many constitutive parameters to describe them." In order to find meaningful data, this study minimizes the complexity of the variables to obtain an ideal solution. The result is data with clearer clinical interpretation, with easier reconstructability, and with less ambiguity.

\section{Testing}

Two different tests were performed to test the effect of calcification on thin cap atheromas. The first test varied calcium and lipid percentages within a constant region. The fibrous cap was varied to find if a relationship existed between cap thickness, calcium/lipid content, and peaks stresses. The second test compared two models that were the same in every feature except one: the first contained calcification and the second contained solely fibrous tissue which replaced the calcium area in the first test.

A transverse cross section geometry was used based on the shape and dimensions used by Li et al. (2007b). A wall thickness of $.75 \mathrm{~mm}$ and crosssection of $10 \mathrm{~mm}$ were used. Li et al. (2006b) and Tang et al. 2005 used a longitudinal cross section, finding that the peak stresses were found at the shoulder region of the stenosis when the fibrous cap was thin. Since the maximum stress in the longitudinal cross-section is located at the shoulder 
region, this study can make the assumption using a transverse cross section that is located at the shoulder region will result in obtaining the true maximum stress.

\section{Constant Areas:}

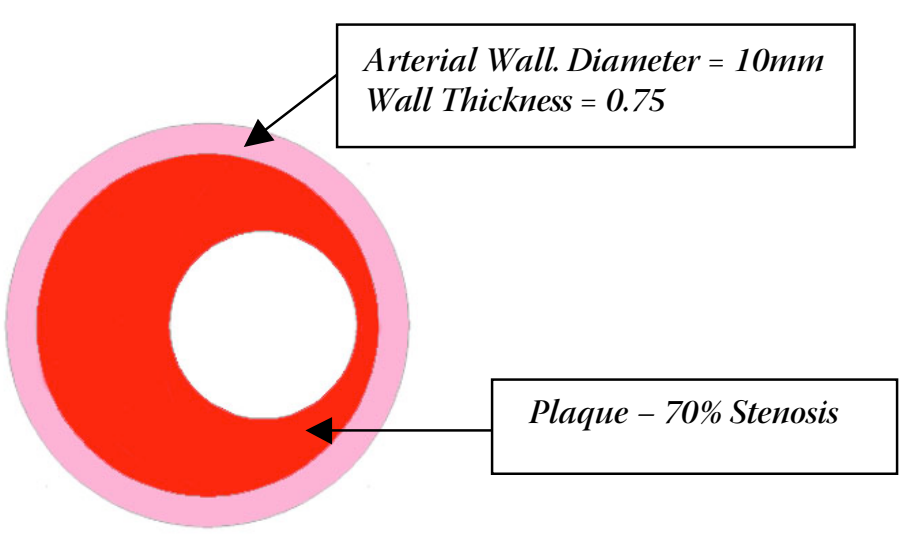

(a)

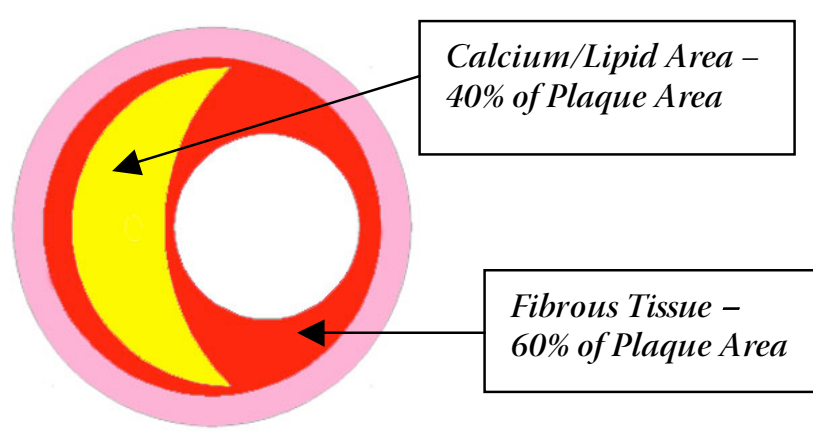

(b)

\section{Variable Areas:}

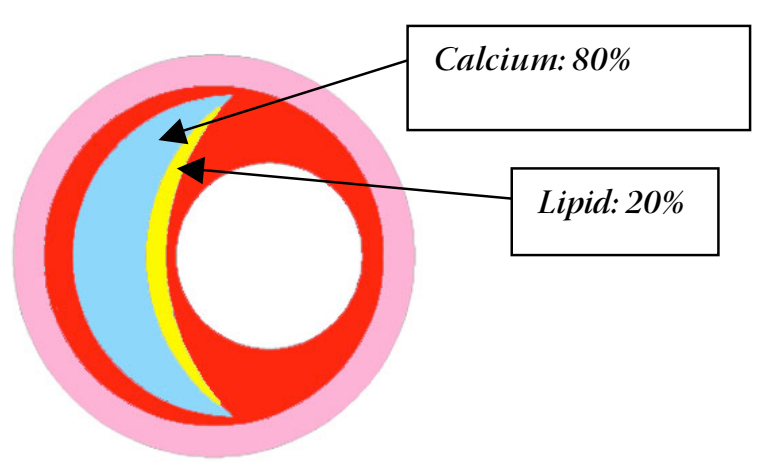

(b)

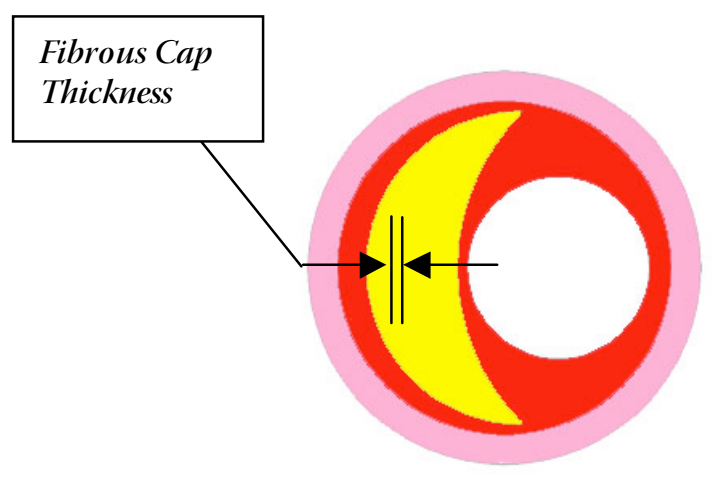

(d)

Figures 11 Four Geometric Diagrams. a) Constant Outer Vessel Diameter of $10 \mathrm{~mm}$, Wall Thickness of $.75 \mathrm{~mm}$, and $70 \%$ Stenosis. b) Constant Calcium Lipid Area at $40 \%$ of Plaque and Fibrous Tissue $50 \%$ of Plaque Area. c) Variable Calcium/Lipid Area. Lipid varies from $0 \%$ to $100 \%$ in $10 \%$ increments.d)Fibrous Cap Thickness Varies at values of $65,90,120,150,250$, and $500 \mu \mathrm{m}$.

For the first test, within the FEM, the combined region of calcium and lipid remained constant. The percentage of calcium and lipid varied from $0 \%$ to $100 \%$ lipid varying by increments of $10 \%$ within this region (see Figure 10c). The 
stenosis remained constant at $70 \%$ (see Figure 10a), the minimum value of the severe stenosis range (according to Li et al. 2006b). The Ca+/lipid area was $40 \%$ of the plaque within the stenosis. Maseri and Fuster (2003) defined the minimum thin cap atheroma as having at least $40 \%$ of the plaque as lipid. The remaining $60 \%$ was classified as fibrous tissue (see figure $10 \mathrm{~b}$ ).

Using COMSOL MultiPhysics, the maximum Von Mises stresses at the thin cap were calculated using linear LaGrange Stresses. The following values, with the exception of the calcification value, were taken from Baldewsing et al. (2004). The elasticity values in this study were based on the general average of compiled data taken from multiple studies on atherosclerotic tissues. No values for calcium were given by Baldewsing et al. (2004). The values for calcium in this study were roughly what Veress et al. 2000 used. Like Baldeswing et al. (2004), this study uses variables that are linear elastic, isotropic plane-strain and nearly incompressible. By depending solely on a linear Young's modulus distribution for obtaining the compressive radial stress, the complexity of the simulation is greatly reduced. By keeping as many variables consistent as possible, this test can hypothesize about the effect of calcium on thin cap atheroma.

Table 7: Material Properties Used in this Study.

\begin{tabular}{|l|c|l|l|}
\hline $\begin{array}{l}\text { Material } \\
\text { Properties }\end{array}$ & $\mathrm{E}(\mathrm{kPa})$ & $\nu$ & $\rho\left(\mathrm{kg} / \mathrm{m}^{3}\right)$ \\
\hline Lipid & 50 & .499 & 1.0 \\
\hline Arterial Wall & 1000 & .499 & 1.0 \\
\hline Fibrous Tissue & 1500 & .499 & 1.0 \\
\hline Calcium & 2000 & .499 & 1.0 \\
\hline
\end{tabular}

Many researchers (Li et al. 2006b, Tang et al. 2005, among others) have used a flow simulation to replicate pulsatile flow Li et al. (2006b) found that the 
impact of shear stress was negligible in comparison to the effect of circumferential pressure. No shear force from the fluid was used. A constant blood pressure of $120 \mathrm{mmHg}$ (approximately $16 \mathrm{kPa}$ ) in the $\mathrm{x}$ and $\mathrm{y}$ direction was used. This was the value of the average pulsatile flow pressure used by Tang et al. (2005). No deformation was allowed.

The fibrous cap thickness was also varied for each set of data (see Figure 10d). The values ranged from 65, 150, 250, and 500 micrometers. Each of these values was tested from $0 \%$ lipid to $100 \%$ lipid. To see if a trend within maximum stress values existed, further cap testing resulted. Cap thicknesses of 90 and 120 microns also were tested at $60 \%$ fibrous $/ 40 \%$ calcified tissue, $70 \%$ fibrous $/ 30 \%$ calcified tissue, $80 \%$ fibrous $/ 20 \%$ calcified tissue, and $90 \%$ fibrous $/ 10 \%$ calcified tissue. Each geometry was tested ten times since variations in the fractals caused variable results. A total of sixty tests were performed for Test 1 . The result correlated fibrous cap thickness, lipid/calcium percent, and peak stress.

The second test used the same geometry and all the same material values as the first test. The second test compared two different models that were identical to the first model except second model had no calcium; fibrous tissue replaced the area of the calcium. Whereas the data in the first test ranged from $0 \%$ lipid to $100 \%$ lipid in $10 \%$ increments, the second model with lipid only ranged from $60 \%$ to $90 \%$. The lipid pool remained the same area as the first test - only the calcium area was replaced. The difference in stress levels was used to determine whether calcium increased or decreased the stability of the fibrous cap. 


\section{Chapter 4: RESULTS}

\section{Test 1:}

As expected, the stress on the cap increased as the cap thickness

decreased. The rate of stress declined steadily when the cap thickness grew greater than 100 microns. When the cap was less than 100 microns, specifically 65 microns, the stress increased an exponential rate.

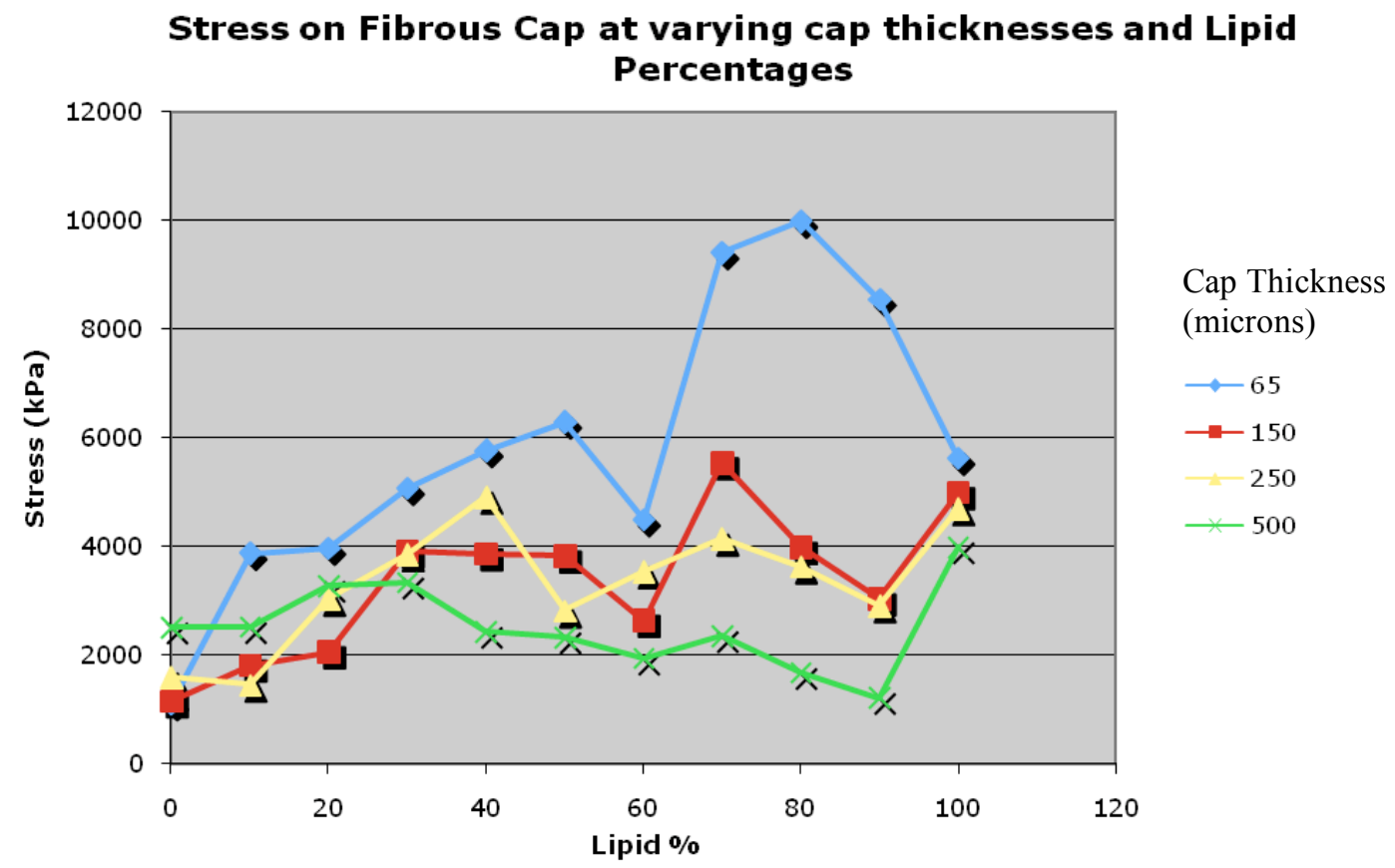

Figure 12. Variations in Peak Stress at Differing Fibrous Cap Thicknesses. Two local maxims can be observed. The change rate of increase could be due to the interplay between lowering the calcification while increasing the lipid pool.

To determine whether a trend between cap thickness and peak stress could be determined, two more cap thicknesses, 90 and 120 microns, were tested. While the maxims did not fit an exponential trend exactly, the extra values showed that the rate of instability increases as the cap thickness decreases (see Fig. 13b). 
Stress Values for Thin cap values of 65, 90, 120, and 150 microns

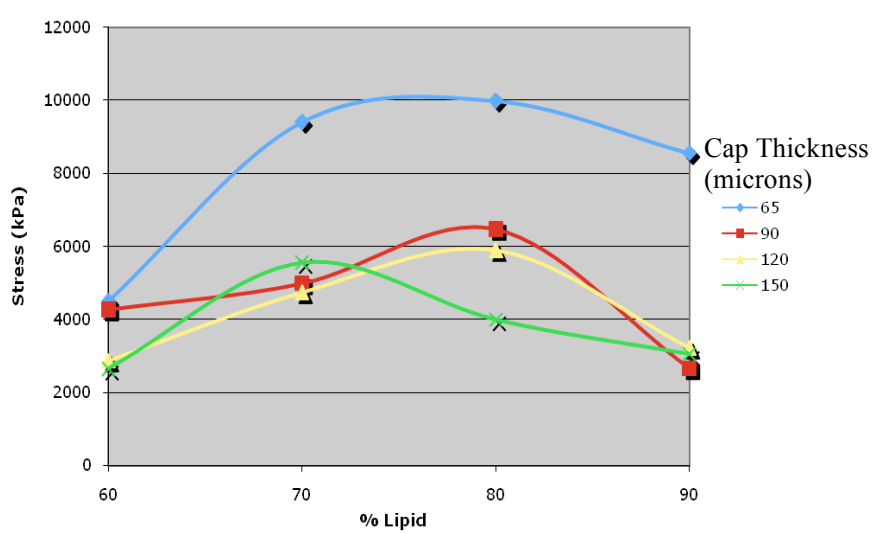

Maximum Stresses for varying cap thickness

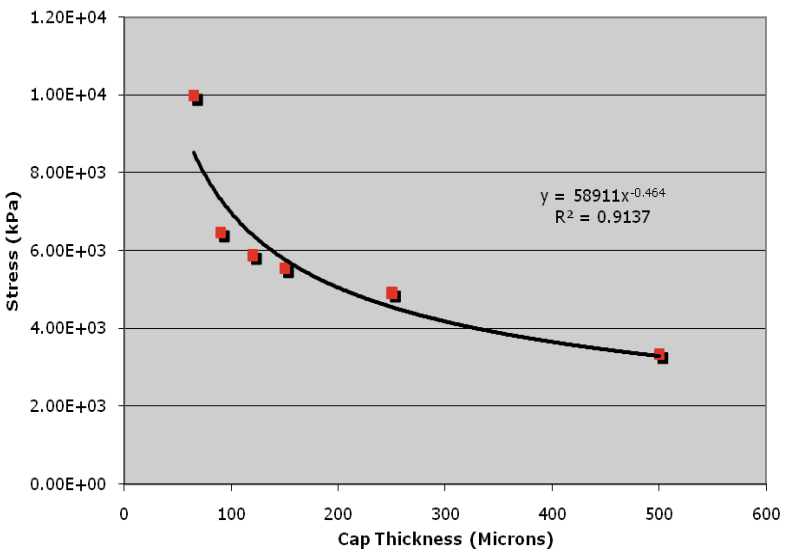

Figures 13a, 13b. Peak Stresses at Various Cap Thicknesses a) Comparison of Peak Stresses for Thin Cap Values 65, 90,120, and 150 microns. Maxims are at $70 \%$ or $80 \%$ lipid. B) Peak stresses increase rapidly when the cap becomes thinner than 90 microns.

With high percentages of calcium and lower percentages of lipid, the overall stress was much lower. This may be due to a smaller lipid pool. Test 2 examines this further. The level of stress drops at $50 \%$ or $60 \%$ lipid for most of the cap thicknesses. This could possibly be due to the declining amount of calcium. If calcium causes increase in stress, the decrease in calcium may be the reason the level of stress drops at fifty percent. However, shortly after that, the stress level rises again. This may occur because the amount of lipid is increasing which causes additional stress on the cap. Test 2 will be helpful in determining the effect of calcium on lipid pool.

The second test found little variation between the first and second model at lipid levels below $50 \%$ of the total lipid/calcium area. At $50 \%$ the calcium stress was lower than the non calcium stress. Above $60 \%$, the calcified model had much higher stress levels. The reason for the stress being more stable at only $60 \%$ is unclear and needs further investigation. 
Thin Cap Stresses with varying lipid percentages and varying thin cap thicknesses

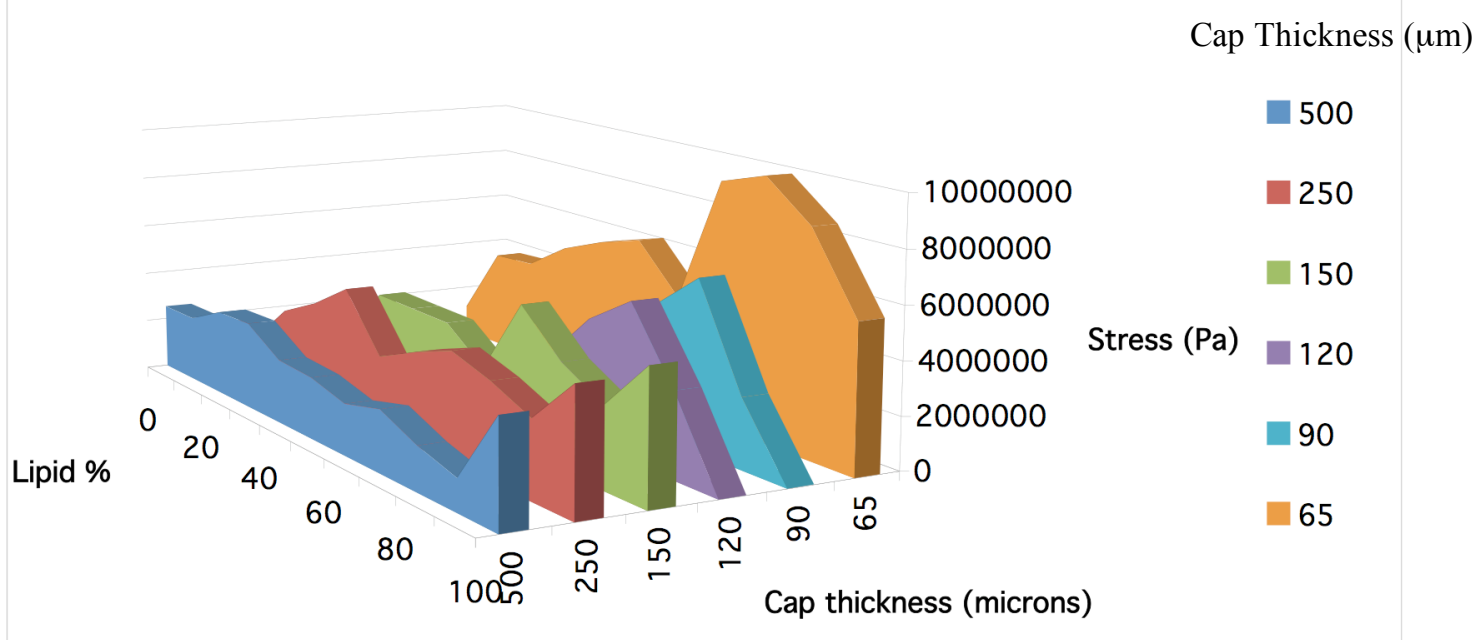

Figure 14. Overview of Peak Stress Data. As the fibrous cap becomes thinner the peak stress increases.

Test 2:

\section{Stress Levels of Thin Cap Atheroma with Calcification and without Calcification}

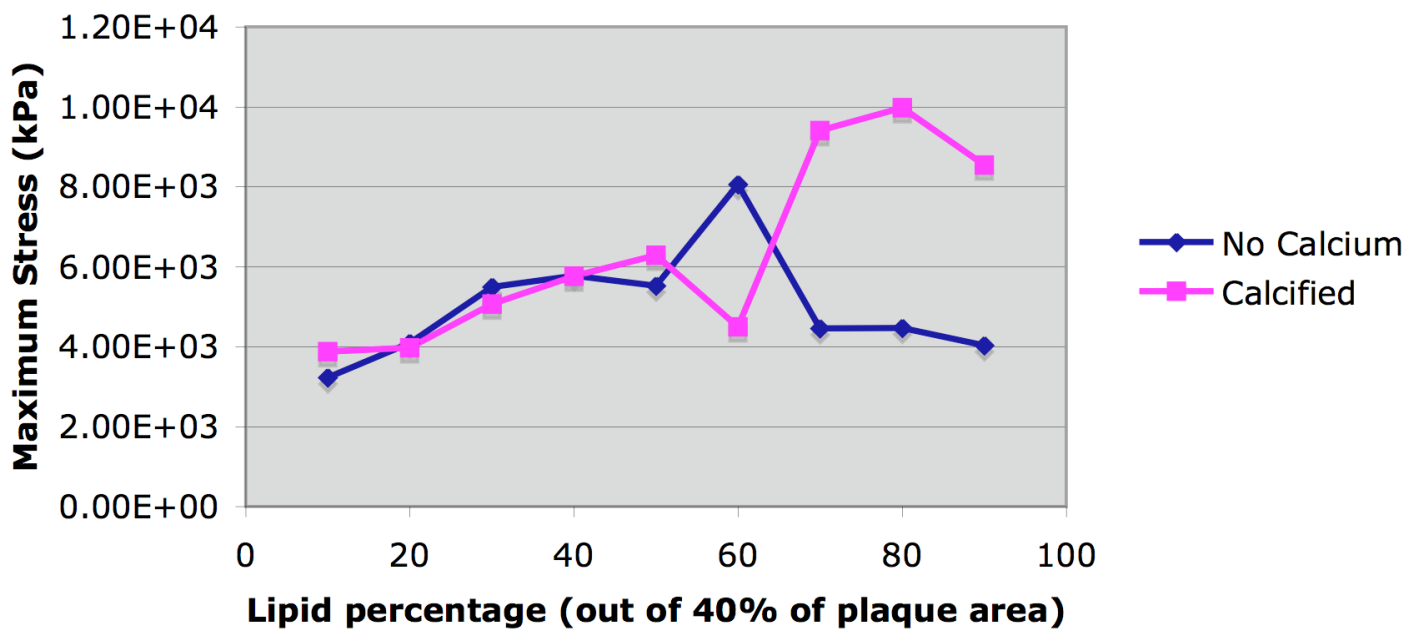

Figure 15. Peak Stress Comparison of Calcified and Noncalcified FEMs. In the calcified model, the stresses increase greatly in lipid pool values when the lipid pool increases over $60 \%$. Calcium seems to have little effect on the stresses at lower lipid levels. When testing the FEMs without calcification, the stresses do not rise dramatically at high lipid levels. Calcium can have a large impact in arteries with larger lipid pools. 
Future studies could take multiple directions in clarifying this result. First, this model could be retested to see if there was error in the data. Next, a new study could vary the fibrous cap to see if this trend occurred at any other values. Also, a new study could increase the lipid pool larger than the areas used in this study to see if calcium continues to affect stress on the fibrous cap. 
Chapter 5: Discussion and Interpretation:

This study found calcium deposits located directly behind the lipid pool resulted in increased peak stresses when the lipid pool became large enough. Contrary to the studies by Li et al 2005 and 2007, calcium distant from the fibrous cap increased peak stress. The overall trend at greater than $60 \%$ Lipid shows the peak stress increased an average of $115 \%$ when calcium was present rather than fibrous tissue. The location and direct proximity of the calcium may cause the increase in stress. In test 1, the stress greatly increased when the thickness of the fibrous cap decreased. When comparing the decrease in stress to the increase in cap thickness, a similar trend can be found in Loree et al. in 1992. As the cap thickness falls below 150 microns, especially at 50 microns, the stress increases exponentially. This critical point also can be seen in the rapid rate of increase in stress between 90 and 65 microns. The question of "how thin is too thin" needs to be answered.

Stress values obtained in this study were roughly $10 x$ greater than those found the Li et al. 2006 when comparing the 100\% lipid in this article to the $70 \%$ stenosis in the Li et al. 2006 paper (Li et al.: (100 $\mu \mathrm{m}$ cap, $530 \mathrm{kPa})(200 \mu \mathrm{m}$ cap, $480 \mathrm{kPa})$, This study: (150 um cap 5,000 kPa), (250 um cap, 4,710 kPa)). The stresses, all within the MPa range, by a large margin exceed the rupture value of $300 \mathrm{kPa}$, set by Huang et al.. The difference in stresses could be due to many factors including the differences in cross-sectional areas, differences in material properties, and the differences in deformation allowances. More 
research is needed to investigate the reason for the high stresses within this study. Even though the stresses may be abnormally high, the trends still provide insight into the effects of calcification.

Overall, FEA is a powerful tool which can provide insight into physiological situations through simulation. The advances in imaging technology are beginning to allow in vivo access to the composition and geometries of plaque regions. Insight into the risk factors of plaque rupture to help generate a risk-based standardized classification system will be a necessary part in preventing Coronary Heart Disease in the future. 


\section{APPENDIX}

\section{Section A: Further Direction Possibilities for FEA analysis}

More tests are necessary to further illuminate the impact of calcification on thin cap atheroma, One test could be to keep a constant calcium area behind a lipid pool and vary the lipid pool from $24 \%$ of the total plaque (which is the $60 \%$ lipid area in this model) to higher values of plaque, probably around $70 \%$ of the total plaque be lipid. I hypothesize that the rising stress compared to lipid \% would show a clearer trend without the of confusion local minimums. Then these values can be compared to models without calcification in the same manner as test 2 in this study.

Differing the geometries for the calcified area could also be explored. This article used a crescent shape and Li et al. (2006b) used a circular shape for the calcium field. A shortened crescent, which didn't span the entire lipid pool, would be one possibility. Asymmetric geometries could also provide insight since real lesions are not symmetric.

Idealized atherosclerotic models have been used in both a 2D longitudinal cross-section ( $\mathrm{Li}$ et al. 2006b) and a 2D transverse longitudinal cross section ( $\mathrm{Li}$ et al. 2007b). 3D models have been used in histological atherosclerotic simulations (Tang et al. 2005) but no 3D ideological model has ever been used. The slope of the stenosis in addition to the \% stenosis affects the stresses upon the lesion. This would provide more variables that need to be accounted when interpreting data. 
Additional adjustments to this test could be to use non-linear properties or transversely isotropic linear elastic properties (Loree et al. 1992, Lee 2000). The Mooney-Rivlin (Huang et al. 2008, Tang et al. 2005, Li et al. 2005) and Ogden (Li et al. 2006b) models are two non-linear models used in the past. Allowing for deformation also might help in giving more accurate information. A pressure function also would give a more realistic picture of the varying stress state within an artery. The combination of these properties has never been used in testing stress states for atherosclerotic lesions with calcification. One needs to keep in mind that a more complicated model will not necessarily provide more insight into learning about atherosclerosis.

\section{Section B: Future directions of predicting rupture risk}

Imaging in vivo arteries has made great leaps in the past few years. There are many differing imaging techniques explored to acquire images that reflect the actual material properties of the artery. Some of these techniques used have been: MRI (Anderson, Li et al 2007, Mitsumori et al., Serefty et al., Tang et al. 2005), Intravascular Ultrasound (IVUS)(Diethrich et al., Irshad et al., Nair et al., Newman et al.), MDCT (Carracosa et al., Galonska et al., Niemen et al.), and Thermo imaging (Cascells et al.). The pulsatile nature of the vascular system has made imaging difficult but recent strides have made progress. Li et al. (2007b) used MRI images based on in vivo images of an artery to create FEMs. In the future, diseased arteries will be able to be imaged and programs which interpret the material properties, stress levels, and rupture risk will be clinically available. 
By evaluating the mechanical vulnerability, in addition to blood vulnerability and myocardial vulnerability, rupture risk may be determined in the future. When high risk areas can be accurately imaged and accessed, preventitive measures can be developed and implemented. A significant segment coronary heart disease fatalities could be prevented.

\section{Section C: Geometry Information}

All geometries were made with COMSOL. The model using created using circles and subtracting the areas not needed.

Outer Arterial Wall:

Center: 0

Radius: 5

Inner Arterial Wall:

Center: 0

Radius: 4.25

\section{Lumen:}

Center: 1.194557

Radius: 1.5

\section{Lipid/Calcium Inner Crescent:}

Center: 0.48126

Radius: 4

\section{Lipid/Calcium Outer Crescent:}

Center: 4.4134

Radius: 5.61164

Inner Crescent 4.4134
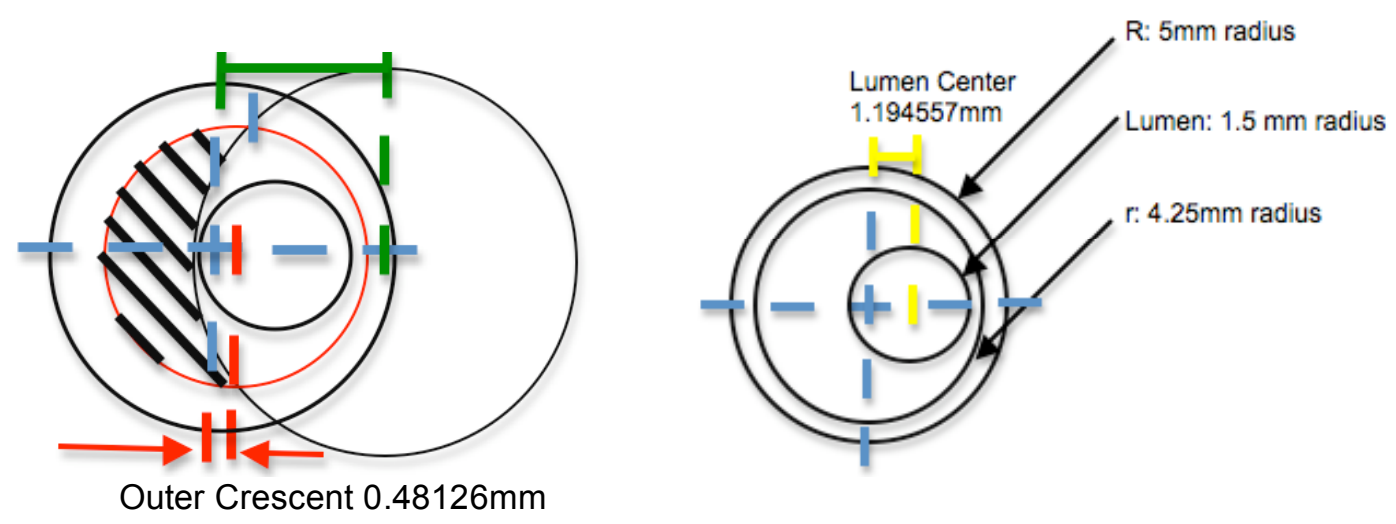

Figures 16a and 16b. Basic Geometry Measurements for Construction in Comsol. The entire geometry is constructed using circles in which the centerpoint is defined on the $x$ axis. The corners of the crescent were rounded then rounded to any false results. 
Table 8. Lipid/Calcium Dividing Line

\begin{tabular}{rrr} 
Percent & \multicolumn{1}{l}{ Radius } & \multicolumn{1}{l}{ Center } \\
10 & 5.08974759 & 3.628567198 \\
20 & 4.73512666 & 3.015314893 \\
30 & 4.488941738 & 2.518563547 \\
40 & 4.31638883 & 2.10336319 \\
50 & 4.19570341 & 1.747724356 \\
60 & 4.112615352 & 1.437088803 \\
70 & 4.057410652 & 1.161395142 \\
80 & 4.023284246 & 0.913484223 \\
90 & 4.005343453 & 0.68808594
\end{tabular}

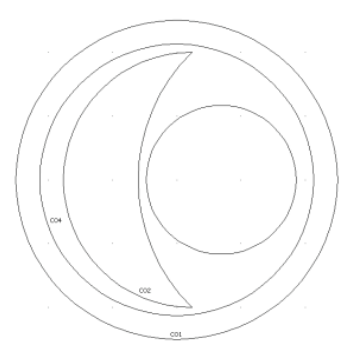

0\% Lipid

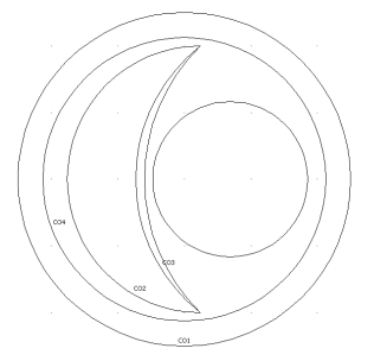

10\% Lipid

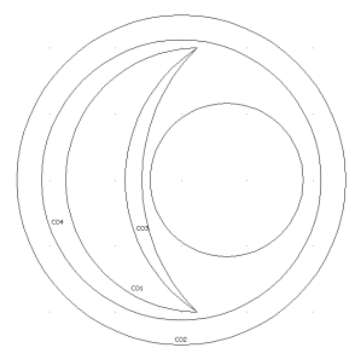

$20 \%$ Lipid

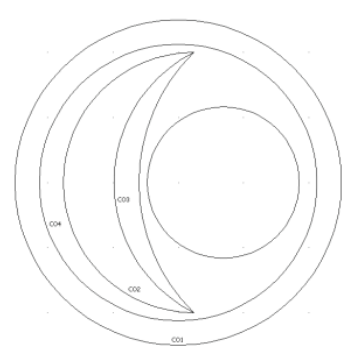

$30 \%$ Lipid

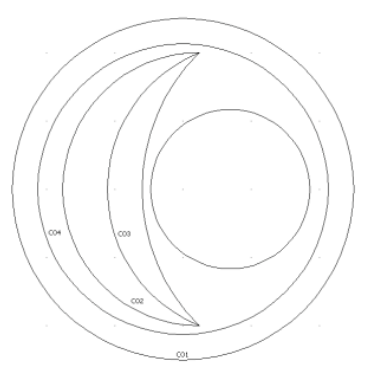

40\% Lipid

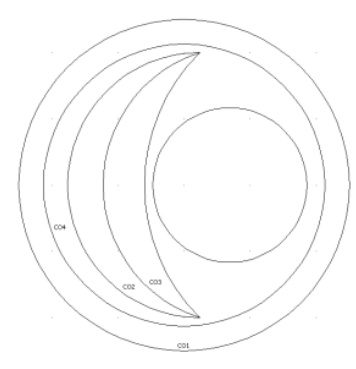

$50 \%$ Lipid

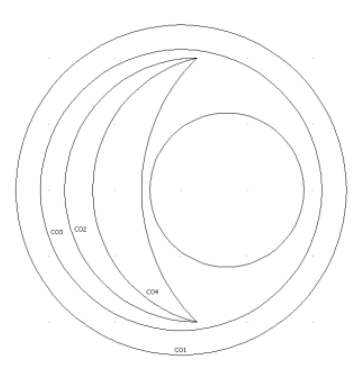

60\% Lipid

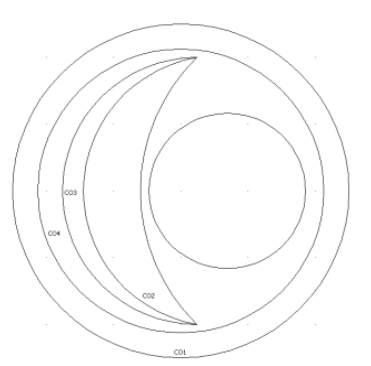

70\% Lipid

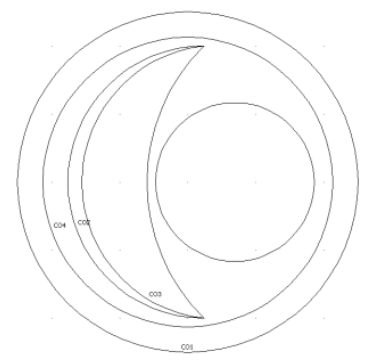

80\% Lipid

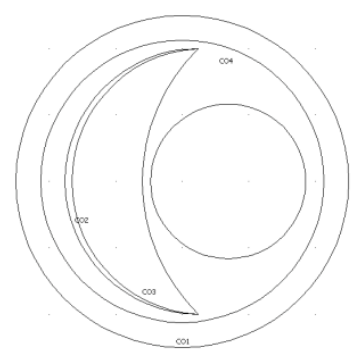

90\% Lipid

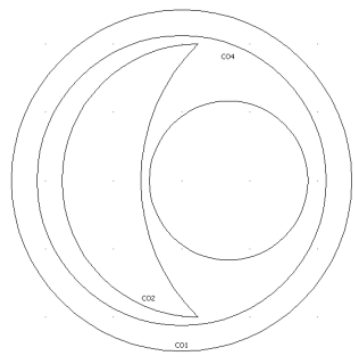

$100 \%$ Lipid

Figure 17. Geometries of all models (shown with a 150 micron cap) from $0 \%$ to $100 \%$ lipid with $10 \%$ increments. 
Ellie Nagy

\section{Section D: Data}

\section{Test 1:}

Table 9: Stress Values (Pa): $65 \mu \mathrm{m}$ Cap Thickness

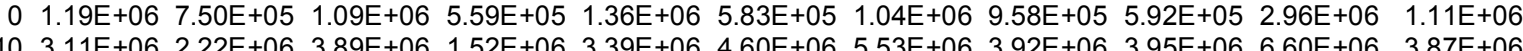

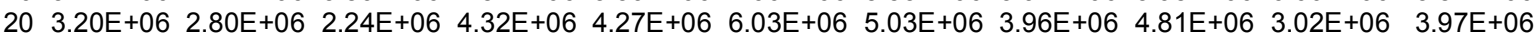

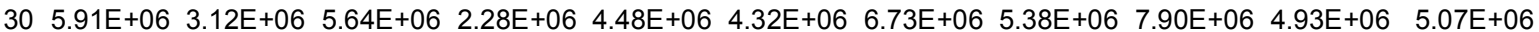

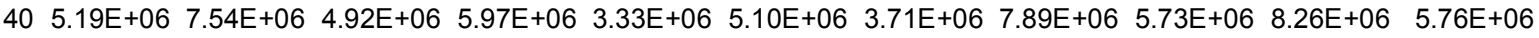

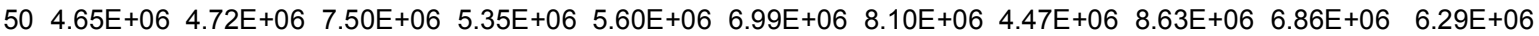

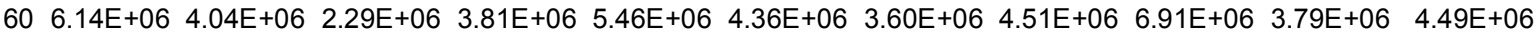

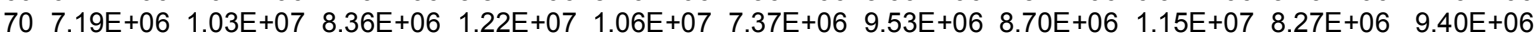

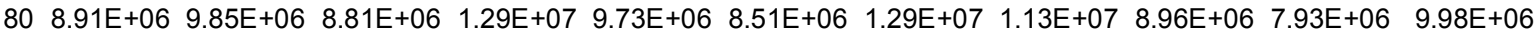

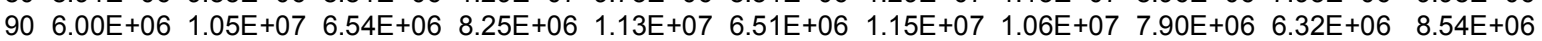

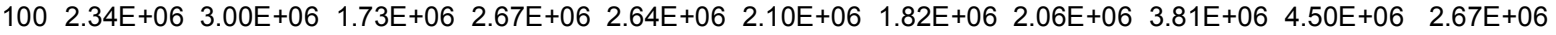

\begin{tabular}{rrrrrrrrrrrrr}
\multicolumn{10}{c}{ Table 10: Stress Values $(\mathrm{Pa}): 150 \mu \mathrm{m}$ Cap Thickness } \\
$\%$ & 1 & 2 & 3 & 4 & 5 & 6 & 7 & 8 & 9 & 10 & AVE \\
0 & $1.40 \mathrm{E}+06$ & $1.86 \mathrm{E}+06$ & $2.86 \mathrm{E}+06$ & $4.75 \mathrm{E}+05$ & $9.74 \mathrm{E}+05$ & $1.25 \mathrm{E}+06$ & $9.45 \mathrm{E}+05$ & $1.02 \mathrm{E}+06$ & $4.56 \mathrm{E}+05$ & $4.46 \mathrm{E}+05$ & $1.17 \mathrm{E}+06$ \\
10 & $4.65 \mathrm{E}+06$ & $1.09 \mathrm{E}+06$ & $4.26 \mathrm{E}+06$ & $7.68 \mathrm{E}+05$ & $4.96 \mathrm{E}+05$ & $5.96 \mathrm{E}+05$ & $1.30 \mathrm{E}+06$ & $1.95 \mathrm{E}+06$ & $9.08 \mathrm{E}+05$ & $2.26 \mathrm{E}+06$ & $1.83 \mathrm{E}+06$ \\
20 & $2.54 \mathrm{E}+06$ & $2.38 \mathrm{E}+06$ & $2.33 \mathrm{E}+06$ & $1.88 \mathrm{E}+06$ & $1.52 \mathrm{E}+06$ & $1.64 \mathrm{E}+06$ & $8.77 \mathrm{E}+05$ & $4.70 \mathrm{E}+06$ & $1.51 \mathrm{E}+06$ & $1.32 \mathrm{E}+06$ & $2.07 \mathrm{E}+06$ \\
30 & $4.56 \mathrm{E}+06$ & $3.47 \mathrm{E}+06$ & $3.86 \mathrm{E}+06$ & $5.04 \mathrm{E}+06$ & $6.22 \mathrm{E}+06$ & $3.02 \mathrm{E}+06$ & $6.40 \mathrm{E}+06$ & $2.91 \mathrm{E}+06$ & $2.01 \mathrm{E}+06$ & $1.77 \mathrm{E}+06$ & $3.93 \mathrm{E}+06$ \\
40 & $2.26 \mathrm{E}+06$ & $4.65 \mathrm{E}+06$ & $5.90 \mathrm{E}+06$ & $3.34 \mathrm{E}+06$ & $3.71 \mathrm{E}+06$ & $4.68 \mathrm{E}+06$ & $4.11 \mathrm{E}+06$ & $1.86 \mathrm{E}+06$ & $3.88 \mathrm{E}+06$ & $2.82 \mathrm{E}+06$ & $3.72 \mathrm{E}+06$ \\
50 & $1.67 \mathrm{E}+06$ & $4.76 \mathrm{E}+06$ & $4.33 \mathrm{E}+06$ & $4.42 \mathrm{E}+06$ & $2.09 \mathrm{E}+06$ & $2.53 \mathrm{E}+06$ & $1.74 \mathrm{E}+06$ & $1.41 \mathrm{E}+06$ & $4.48 \mathrm{E}+06$ & $4.82 \mathrm{E}+06$ & $3.23 \mathrm{E}+06$ \\
60 & $1.19 \mathrm{E}+06$ & $1.13 \mathrm{E}+06$ & $2.44 \mathrm{E}+06$ & $3.22 \mathrm{E}+06$ & $1.37 \mathrm{E}+06$ & $1.79 \mathrm{E}+06$ & $3.33 \mathrm{E}+06$ & $2.26 \mathrm{E}+06$ & $2.36 \mathrm{E}+06$ & $1.58 \mathrm{E}+06$ & $2.07 \mathrm{E}+06$ \\
70 & $3.89 \mathrm{E}+06$ & $3.38 \mathrm{E}+06$ & $5.71 \mathrm{E}+06$ & $6.00 \mathrm{E}+06$ & $3.86 \mathrm{E}+06$ & $4.46 \mathrm{E}+06$ & $3.84 \mathrm{E}+06$ & $2.59 \mathrm{E}+06$ & $1.98 \mathrm{E}+06$ & $6.05 \mathrm{E}+06$ & $4.18 \mathrm{E}+06$ \\
80 & $1.57 \mathrm{E}+06$ & $1.56 \mathrm{E}+06$ & $4.56 \mathrm{E}+06$ & $4.19 \mathrm{E}+06$ & $2.41 \mathrm{E}+06$ & $3.27 \mathrm{E}+06$ & $2.85 \mathrm{E}+06$ & $4.34 \mathrm{E}+06$ & $3.26 \mathrm{E}+06$ & $2.10 \mathrm{E}+06$ & $3.01 \mathrm{E}+06$ \\
90 & $2.38 \mathrm{E}+06$ & $3.31 \mathrm{E}+06$ & $1.35 \mathrm{E}+06$ & $4.11 \mathrm{E}+06$ & $4.00 \mathrm{E}+06$ & $3.67 \mathrm{E}+06$ & $4.82 \mathrm{E}+06$ & $2.74 \mathrm{E}+06$ & $2.97 \mathrm{E}+06$ & $1.11 \mathrm{E}+06$ & $3.05 \mathrm{E}+06$ \\
100 & $4.04 \mathrm{E}+06$ & $5.33 \mathrm{E}+06$ & $3.96 \mathrm{E}+06$ & $3.13 \mathrm{E}+06$ & $6.09 \mathrm{E}+06$ & $5.50 \mathrm{E}+06$ & $1.96 \mathrm{E}+06$ & $3.17 \mathrm{E}+06$ & $5.01 \mathrm{E}+06$ & $2.26 \mathrm{E}+06$ & $4.05 \mathrm{E}+06$
\end{tabular}

\begin{tabular}{rrrrrrrrrrrr}
\multicolumn{10}{c}{ Table 11: Stress Values $(\mathrm{Pa}): 250 \mu \mathrm{m}$ Cap Thickness } & & \\
$\%$ & 1 & 2 & 3 & 4 & 5 & 6 & 7 & 8 & 9 & 10 \\
0 & $1.36 \mathrm{E}+06$ & $6.93 \mathrm{E}+05$ & $3.52 \mathrm{E}+06$ & $3.22 \mathrm{E}+06$ & $1.16 \mathrm{E}+06$ & $2.44 \mathrm{E}+06$ & $6.99 \mathrm{E}+05$ & $5.09 \mathrm{E}+05$ & $1.91 \mathrm{E}+06$ & $4.31 \mathrm{E}+05$ & $1.59 \mathrm{E}+06$ \\
10 & $1.02 \mathrm{E}+06$ & $3.10 \mathrm{E}+06$ & $1.83 \mathrm{E}+06$ & $7.45 \mathrm{E}+05$ & $2.38 \mathrm{E}+06$ & $1.23 \mathrm{E}+06$ & $1.05 \mathrm{E}+06$ & $9.96 \mathrm{E}+05$ & $1.09 \mathrm{E}+06$ & $1.17 \mathrm{E}+06$ & $1.46 \mathrm{E}+06$ \\
20 & $1.49 \mathrm{E}+06$ & $3.46 \mathrm{E}+06$ & $2.11 \mathrm{E}+06$ & $3.11 \mathrm{E}+06$ & $1.16 \mathrm{E}+06$ & $3.08 \mathrm{E}+06$ & $2.66 \mathrm{E}+06$ & $4.93 \mathrm{E}+06$ & $4.12 \mathrm{E}+06$ & $4.30 \mathrm{E}+06$ & $3.04 \mathrm{E}+06$ \\
30 & $4.03 \mathrm{E}+06$ & $4.73 \mathrm{E}+06$ & $2.11 \mathrm{E}+06$ & $3.25 \mathrm{E}+06$ & $2.90 \mathrm{E}+06$ & $5.69 \mathrm{E}+06$ & $4.38 \mathrm{E}+06$ & $4.73 \mathrm{E}+06$ & $2.10 \mathrm{E}+06$ & $4.71 \mathrm{E}+06$ & $3.86 \mathrm{E}+06$ \\
40 & $4.34 \mathrm{E}+06$ & $6.06 \mathrm{E}+06$ & $4.57 \mathrm{E}+06$ & $5.56 \mathrm{E}+06$ & $4.33 \mathrm{E}+06$ & $4.44 \mathrm{E}+06$ & $5.27 \mathrm{E}+06$ & $3.62 \mathrm{E}+06$ & $5.69 \mathrm{E}+06$ & $5.33 \mathrm{E}+06$ & $4.92 \mathrm{E}+06$ \\
50 & $1.72 \mathrm{E}+06$ & $1.61 \mathrm{E}+06$ & $1.74 \mathrm{E}+06$ & $3.98 \mathrm{E}+06$ & $5.73 \mathrm{E}+06$ & $4.98 \mathrm{E}+06$ & $2.36 \mathrm{E}+06$ & $1.74 \mathrm{E}+06$ & $1.51 \mathrm{E}+06$ & $2.88 \mathrm{E}+06$ & $2.83 \mathrm{E}+06$ \\
60 & $5.67 \mathrm{E}+06$ & $3.60 \mathrm{E}+06$ & $3.40 \mathrm{E}+06$ & $4.56 \mathrm{E}+06$ & $3.15 \mathrm{E}+06$ & $5.37 \mathrm{E}+06$ & $2.68 \mathrm{E}+06$ & $2.43 \mathrm{E}+06$ & $1.41 \mathrm{E}+06$ & $3.19 \mathrm{E}+06$ & $3.55 \mathrm{E}+06$ \\
70 & $3.38 \mathrm{E}+06$ & $6.73 \mathrm{E}+06$ & $3.89 \mathrm{E}+06$ & $2.86 \mathrm{E}+06$ & $6.68 \mathrm{E}+06$ & $2.16 \mathrm{E}+06$ & $4.03 \mathrm{E}+06$ & $5.26 \mathrm{E}+06$ & $2.19 \mathrm{E}+06$ & $4.32 \mathrm{E}+06$ & $4.15 \mathrm{E}+06$ \\
80 & $3.33 \mathrm{E}+06$ & $6.01 \mathrm{E}+06$ & $2.54 \mathrm{E}+06$ & $5.48 \mathrm{E}+06$ & $1.71 \mathrm{E}+06$ & $3.35 \mathrm{E}+06$ & $2.87 \mathrm{E}+06$ & $3.36 \mathrm{E}+06$ & $1.13 \mathrm{E}+06$ & $6.58 \mathrm{E}+06$ & $3.64 \mathrm{E}+06$ \\
90 & $4.36 \mathrm{E}+06$ & $3.37 \mathrm{E}+06$ & $3.56 \mathrm{E}+06$ & $2.65 \mathrm{E}+06$ & $3.81 \mathrm{E}+06$ & $1.31 \mathrm{E}+06$ & $1.04 \mathrm{E}+06$ & $3.82 \mathrm{E}+06$ & $1.98 \mathrm{E}+06$ & $3.31 \mathrm{E}+06$ & $2.92 \mathrm{E}+06$ \\
100 & $5.38 \mathrm{E}+06$ & $4.99 \mathrm{E}+06$ & $6.64 \mathrm{E}+06$ & $4.54 \mathrm{E}+06$ & $2.90 \mathrm{E}+06$ & $2.56 \mathrm{E}+06$ & $5.36 \mathrm{E}+06$ & $8.12 \mathrm{E}+06$ & $5.33 \mathrm{E}+06$ & $6.12 \mathrm{E}+06$ & $5.19 \mathrm{E}+06$
\end{tabular}


Table 12: Stress Values (Pa): $500 \mu \mathrm{m}$ Cap Thickness

\begin{tabular}{|c|c|c|c|c|c|c|c|c|c|c|c|}
\hline & 1 & 2 & 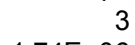 & 4 & $\checkmark$ & 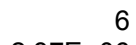 & 1 & & & & \\
\hline 0 & +06 & +06 & +06 & +06 & +06 & +06 & +06 & $E+06$ & $E+06$ & & \\
\hline 10 & +06 & & & & & & & & & & \\
\hline 20 & & & & & & & & & & & \\
\hline 3 & & & & & & & & & & & \\
\hline 4 & & & & & & & & & & & \\
\hline 5 & & & & & & & & & & & \\
\hline 6 & & & & & & & & & & & \\
\hline & & & & & & & & & & & \\
\hline & & & & & & & & & & & \\
\hline 9 & & +06 & & & & & +06 & $E+05$ & +06 & +05 & 1.2 \\
\hline & TUO & +06 & $J 0$ & $=-T 00$ & TUO & $5.83 E+06$ & $5 \mathrm{E}+06$ & $3.83 E+06$ & $1 \mathrm{E}+06$ & $2.69 \mathrm{E}+06$ & \\
\hline
\end{tabular}

Table 13: Stress Values (Pa): $90 \mu \mathrm{m}$ Cap Thickness

\begin{tabular}{|c|c|c|c|c|c|c|c|c|c|c|}
\hline 1 & 2 & 3 & 4 & 5 & 6 & 7 & 8 & 9 & 10 & \\
\hline 6 & +06 & 6 & 06 & $E+06$ & 06 & $5+0$ & 6 & 6 & 6 & \\
\hline & & & & & & & & & & \\
\hline & & & & & & & & & & \\
\hline & +06 & & +06 & +06 & $E+06$ & $E+06$ & $1.05 E+06$ & $0 \mathrm{E}+06$ & $2.42 \mathrm{E}+06$ & $2.66 \mathrm{E}$ \\
\hline
\end{tabular}

Table 14: Stress Values $(\mathrm{Pa}): 120 \mu \mathrm{m}$ Cap Thickness

\begin{tabular}{|c|c|c|c|c|c|c|c|c|c|c|}
\hline 1 & 2 & 3 & 4 & 5 & 6 & 7 & 8 & 9 & 10 & \\
\hline 6 & & & & 6 & & & & & & \\
\hline & & & & & & & & & & \\
\hline & & & & & & & & & & \\
\hline & -0 & +06 & +06 & 06 & 66 & 06 & $86 \mathrm{E}+06$ & $E+06$ & .5 & \\
\hline
\end{tabular}

Table 15: Stress Values (Pa): Compiled Average Stress Values

\begin{tabular}{|c|c|c|c|c|c|c|}
\hline$\%$ & $65(\mu \mathrm{m})$ & $90(\mu \mathrm{m})$ & $120(\mu \mathrm{m})$ & $150(\mu \mathrm{m})$ & $250(\mu \mathrm{m})$ & $500(\mu \mathrm{m})$ \\
\hline 0 & $1.11 \mathrm{E}+06$ & & & $1.17 E+06$ & $1.59 \mathrm{E}+06$ & $2.51 \mathrm{E}+06$ \\
\hline 10 & $3.87 E+06$ & & & $1.83 E+06$ & $1.46 \mathrm{E}+06$ & $2.52 E+06$ \\
\hline 20 & $3.97 E+06$ & & & $2.07 \mathrm{E}+06$ & $3.04 E+06$ & $3.28 E+06$ \\
\hline 30 & $5.07 \mathrm{E}+06$ & & & $3.93 E+06$ & $3.86 \mathrm{E}+06$ & $3.34 \mathrm{E}+06$ \\
\hline 40 & $5.76 \mathrm{E}+06$ & & & $3.88 E+06$ & $4.92 E+06$ & $2.43 E+06$ \\
\hline 50 & $6.29 \mathrm{E}+06$ & & & $3.83 E+06$ & $2.83 E+06$ & $2.33 E+06$ \\
\hline 60 & $4.49 \mathrm{E}+06$ & $4.27 \mathrm{E}+06$ & $2.87 E+06$ & $2.65 E+06$ & $3.55 E+06$ & $1.94 E+06$ \\
\hline 70 & $9.40 \mathrm{E}+06$ & $4.99 E+06$ & $4.74 \mathrm{E}+06$ & $5.55 \mathrm{E}+06$ & $4.15 E+06$ & $2.36 \mathrm{E}+06$ \\
\hline 80 & $9.98 \mathrm{E}+06$ & $6.48 \mathrm{E}+06$ & $5.90 \mathrm{E}+06$ & $3.99 \mathrm{E}+06$ & $3.64 \mathrm{E}+06$ & $1.68 \mathrm{E}+06$ \\
\hline 90 & $8.54 \mathrm{E}+06$ & $2.66 \mathrm{E}+06$ & $3.22 E+06$ & $3.05 E+06$ & $2.92 E+06$ & $1.22 E+06$ \\
\hline 100 & 5.62 & & & $5.00 \mathrm{E}+06$ & $4.71 \mathrm{E}+06$ & $3.99 \mathrm{E}+$ \\
\hline
\end{tabular}

\section{Test 2 :}

Table 16: Stress results (Pa): No Calcification

\begin{tabular}{|c|c|c|c|c|c|c|c|c|c|c|}
\hline 1 & 2 & 3 & 4 & 5 & 6 & 7 & 8 & 9 & 10 & verage \\
\hline $4.34 \mathrm{E}+06$ & $98 \mathrm{E}+06$ & $3.59 \mathrm{E}+06$ & $3.51 \mathrm{E}+06$ & $2.91 \mathrm{E}+06$ & $2.05 E+06$ & $2.91 \mathrm{E}+06$ & $5.13 \mathrm{E}+06$ & $3.81 \mathrm{E}+06$ & $2.02 \mathrm{E}+06$ & +06 \\
\hline L & $69 \mathrm{E}+06$ & $83 E+06$ & $7 \mathrm{E}+1$ & $3.26 \mathrm{E}+06$ & 6 & 2. & 6 & 6 & 6 & 6 \\
\hline $5.24 \mathrm{E}+06$ & $7.86 \mathrm{E}+06$ & $3.53 \mathrm{E}+06$ & $3.96 \mathrm{E}+06$ & $5.41 \mathrm{E}+06$ & $5 E+06$ & $6 \mathrm{E}+06$ & $2 E+06$ & 6 & 6 & 66 \\
\hline $6.74 \mathrm{E}+06$ & +06 & $4.59 \mathrm{E}+06$ & $6.87 \mathrm{E}+06$ & $8.61 \mathrm{E}+06$ & +06 & $4.67 E+06$ & $6.02 \mathrm{E}+06$ & 06 & 06 & $5.78 \mathrm{E}$ \\
\hline $3.88 \mathrm{E}$ & 4.9 & 6.0 & $6.50 \mathrm{E}+06$ & $3 . \varepsilon$ & +06 & 6. & & & & \\
\hline+06 & 7.1 & $E+06$ & $E+06$ & +06 & $E+06$ & +06 & +06 & +06 & +06 & $8.06 \mathrm{E}+06$ \\
\hline+06 & 4.1 & +06 & $=06$ & +06 & $E+06$ & +06 & +06 & +06 & -06 & +06 \\
\hline+06 & +06 & $: 06$ & +06 & +06 & $E+06$ & +06 & $E+06$ & 06 & & +06 \\
\hline 06 & 3.72 & 1.5 & 2.91 & 4.91 & $3.90 E+06$ & $6.58 \mathrm{E}+06$ & $5.97 \mathrm{E}+06$ & $6.20 \mathrm{E}+06$ & $2.16 \mathrm{E}+06$ & 4.0 \\
\hline
\end{tabular}




\section{Bibliography}

American Heart Association "Cardiovascular Disease Statistics." 6 Feb. 2008

$<w w w . a m e r i c a n h e a r t . o r g>$ Path: Seach; Cardiovascular Disease Statistics.

Anderson, Russell W. et al. "Automated Classification of Atherosclerotic Plaque from Magnetic Resonance Images Using Predictive Models." Biosystems 90 (2007): 15 Jan. 2008 <http://mythic.lib.calpoly.edu:2100/science?_ob=ArticleURL\&udi=B6T2K4MC81PH1\&_user $=521828 \&$ coverDate $=10 \% 2 \mathrm{~F} 31 \% 2 \mathrm{~F} 2007 \&$ alid $=745502435 \&$ rdoc $=1 \&$ fmt $=$ high \&_orig=search\&_cdi $=4921 \&$ sort $=\mathrm{d} \& \_d o c a n c h o r=\& v i e w=c \&$ ct $=1 \&$ acct $=C 000059579$ \& version $=1 \&$ urlVersion $=0 \&$ userid $=521828 \& \mathrm{md} 5=4 \mathrm{bd} 5 \mathrm{~d} 2388 \mathrm{~d} 6 \mathrm{~d} 4 \mathrm{4} 611707834 \mathrm{cf} 163 \mathrm{dad} 9>$.

Baldewsing Radj A. et al. "A Finite Element Model for Performing Intravascular Ultrasound Elastography of Human Atherosclerotic Coronary Arteries." Ultrasound in Med. \& Bio 30:6 (2004): 803-811. 28 Mar. 2008 <http://www.sciencedirect.com/science?_ob= ArticleURL\&_udi=B6TD2-4CPJMGN-D\&_user=10\&_rdoc=1\&_fmt=\&_orig=search\&_sort $=\mathrm{d} \&$ view $=c \&$ acct $=\mathrm{C} 000050221 \&$ _version $=1 \&$ _urlVersion $=0 \&$ _userid $=10 \& \mathrm{md} 5=4 \mathrm{f} 8 \mathrm{~d} 9 \mathrm{ff} 62834 \mathrm{ed}$ $84 \mathrm{c} 478 \mathrm{~b} 79 \mathrm{e}-\bar{a} \mathrm{e} 7 \mathrm{e} 778>$

Cai, Jian-Ming. et al. "Classification of Human Carotid Atherosclerotic Lesions with in vivo Multicontrast Magnetic Resonance Imaging." Circulation 106 (2002): 1368-1373. 13 Feb. 2008 <http://circ.ahajournals.org/cgi/content/full/106/11/1368>

Campbell, G.R. and J. H. Campbell. "Vascular Smooth Muscle and Arterial Calcification." Z. Kardiol 89:2 (2000): II/54-II/64. 31 Jan. 2008 <http://mythic.lib.calpoly.edu:2133/ content/fb6l5qruc2n89e66/>

Carrascosa, Patricia M. et al. "Characterization of Coronary Athersclerotic Plaques by Multidetector Computed Tomography." Am J Cardiol 97 (2006): 598-602. 26 Jan. 2008 $<$ http://www.sciencedirect.com/science?_ob=ArticleURL\&_udi=B6T10-4J13W1C$2 \&$ user $=10 \& \_r d o c=1 \&$ fmt $=$ \&_orig $=$ search\&_sort $=d \& v i e w=c \&$ acct $=C 000050221 \&$ _version $=1$ \&_urlVersion=0\&_userid $=10 \& \mathrm{md} 5=37 f 50413631 \mathrm{fc} 966664624 \mathrm{c} 692487415>$

Casscells, Naghavi, and James T. Willerson. "Vulnerable Atherosclerotic Plaque: A Multifocal Disease." Circulation 107 (2003): 2072-2075. 29 Jan. 2008 <http://circ.ahajournals. org/cgi/content/short/107/16/2072>

Cheng, George C. "Distribution of Circumferential Stress in Ruptured and Stable Atherosclerotic Lesions. A Structural Analysis with Histopathological Correlation." Circulation 87 (1993): 11791187. 31 Jan. $2008<$ http://circ.ahajournals.org/ cgi/reprint/87/4/1179>

Davies, Michael J. "Stability and Instability: Two Faces of Coronary Atherosclerosis." Circulation 94 (1996): 2013-2020. 29 Jan. 2008 <http://circ.ahajournals.org/ cgi/content/full/94/8/2013>

Delfino A., et al. "Residual Strain Effects on the Stress Field in a Thick Wall Finite Element Model of the Human Carotid Bifurcation." J Biomechanics 30:8 (1997): 777-786. 28 Jan. 2008. $<$ http://www.sciencedirect.com/science?_ob=ArticleURL\&_udi=B6T82-3RH6D8F$\mathrm{N} \&$ user $=10 \&$ rdoc $=1 \& \_\mathrm{fmt}=$ \&_orig $=$ search\&_sort $=\mathrm{d} \& \mathrm{view}=\mathrm{c} \&$ acct 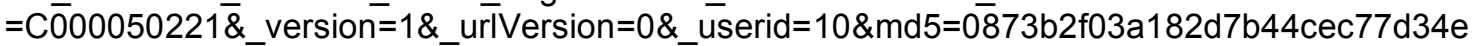 $5700 f>$ 
Deneke,T., et al. "Atherosclerotic Carotid Arteries- Calcification and Radio-Morphological Findings." Z. Kardiol 89:2 (2000): II/36-II/48. 31 Jan. 2008 <http://mythic.lib. calpoly.edu:2133/content/ydju0790w4tltk3f/>

Diethrich, Edward B., et al. "Virtual Histology Intravascular Ultrasound Assessment of Carotid Artery Disease: The Carotid Artery Plaque Histology Evaluation (CAPITAL) Study." J Endovasc Ther 14 (2007): 676-686. 15 Feb. 2008 <http://jevt.allenpre ss.com/enthonline/?request=get-abstract\&issn=1545-1550\&volume=14\&page=676>

Finet, Ohayon, and Gilles Rioufol. "Biomechanical Interaction Between Cap Thickness, Lipid Core Composition and Blood Pressure in Vulnerable Coronary Plaque: Impact on Stability or Instability." Coronary Artery Disease 15 (2004): 13-20. 15 Feb. 2008 <http://www.coronaryartery.com/pt/re/cad/abstract.00019501-200402000-

00003.htm;jsessionid=L2pP2mHRnRJCyFrXyjpPMN2BYdhwMVDIncGBQXyb6JQbJ9zmTG9L!1 $95308708 ! 181195628 ! 8091 !-1>$

Friedman, Morton H. and Don P. Giddens. "Blood Flow in Major Blood Vessels- Modeling and Experiments." Annals of Biomedical Engineering 33:12 (2005): 1710-1713. 3 Jan. 2008 <http://www.springerlink.com/content/p5xt615h32130755/>

Fung, Y.C. and S. Q. Liu. "Determination of the Mechanical Properties of the Different Layers of Blood Vessels in vivo." Proc. Natl. Acad. Aci USA 92 (1995): 2169-2173. 28 Jan. 2008 $<$ http://www.pubmedcentral.nih.gov/articlerender.fcgi?tool=pubmed\&pubmedid= $7892241>$

Galonska, Maximilian, et al. "Characterization of Atherosclerotic Plaques in Human Coronary Arteries with 16-Slice Multidetector Row Computed Tomography by Analysis of Attenuation Profiles." Acad Radiol 15 (2008): 222-230. 15 Feb. 2008 <http://www.sci encedirect.com/science?_ob=ArticleURL\&_udi=B75BK-4RKVHMH-D\&_user=10\&_rdoc= $1 \&$ fmt $=$ \&_orig=search\&_sort $=\mathrm{d} \&$ view $=\mathrm{c} \&$ _acct $=\mathrm{C} 000050221$ \&_version $=1$ \&_urlVersion=0\&_use

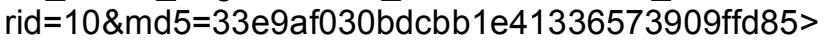

Gasser, T. Christian and Gerhard A. Holzapfel. "Modeling Plaque Fissuring and Dissection During Balloon Angioplasty Intervention." Annals of Biomedical Engineering 35:5 (2007): 711-723. 5 Feb. $2008<$ http://www.springerlink.com/content/y6k2527u5n366r95/>

Glagov, S., et al. "Mechanical Determinants of Plaque Modeling, Remodeling and Disruption." Atherosclerosis 131 (1997): S12-S14. 3 Feb. 2008 <http://mythic.lib.calpoly.edu:2100/science/journal/00219150>

Hayward, Davies, and P. M. Lamont. "Carotid Plaque Morphology: A Review." Eur J Vac Endovasc Surg 9 (1995): 368-374. 21 Feb. 2008 <http://www.sciencedirect.com/science?_ob=ArticleURL\&_udi=B6WF5-4H28M08-

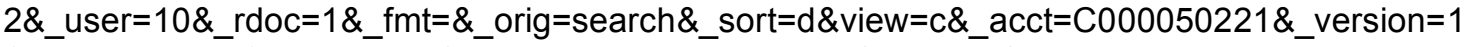
\&_urlVersion=0\&_userid $=10 \& \mathrm{md} 5=\mathrm{e} 6 \mathrm{e} 14 \mathrm{~b} 7 \mathrm{e} 2710 \mathrm{~b} 944 \mathrm{f} 5420 \mathrm{aa0} 2 \mathrm{fc} 6 \mathrm{e} 532>$

Holzapfel, Gerhard A., et al. "Determination of Layer-Specific Mechanical Properties of Human Coronary Arteries with Nonatherosclerotic Intimal Thickening and Related Constitutive Modeling." Am J Phsiol Heart Circ Physiol 289 (2005): 2048-2058. 4 Jan. 2008 <http://ajpheart.physiology.org/cgi/content/full/289/5/H2048>

Holzapfel, Stadler, and Christina A. J. Schulze-Bauer. "A Layer-Specific Three-Dimensional Model for the Simulation of Balloon Angioplasty using Magnetic Resonance Imaging and Mehanical Testing." Annals of Biomedical Engineering 30 (2002): 753-767. 4 Jan. 2008 <http://www.springerlink.com/content/v67540036k26637n/> 
Huang, Hayden, et al. "The Impact of Calcification of the Biomechanical Stability of Atherosclerotic Plaques." Circulation 103 (2001): 1051-1056. 28 Jan. 2008

<http://circ.ahajournals.org/cgi/content/full/103/8/1051>

Irshad, Khalid, et al. "Virtual Histology Intravascular Ultrasound in Carotid Interventions." J Endovasc Ther 14 (2007): 198-207. 15 Feb. 2008 <http://circ.ahajournals.org/

cgi/content/full/103/8/1051>

Kereiakes, Dean J. "The Emperor's Clothes: in Search of the Vulnerable Plaque." Circulation 107 (2003): 2076-2077. 5 Feb. 2008 <http://circ.ahajournals.org/cgi/content/ full/107/16/2076>

Kolodgie, F.D., et al. "Pathologic Assessment of the Vulnerable Human Coronary Plaque." Heart 90 (2004): 1385-1391. 15 Feb. 2008 <http://heart.bmj.com/cgi/content/ full/90/12/1385>

Kuhl, E., et al. "Computational Modeling of Arterial Wall Growth - Attempts Toward Patient-Specific Situations Based on Computer Tomography." Biomechan Model Mechanobiol 6 (2007): 321331. 4 Jan. $2008<$ http://mythic.lib.calpoly.edu:2133/content/ q7u531p31608u585/>

Lee, K. W. and X. Y. Xu. "Modelling of Flow and Wall Behavior in a Mildly Stenosed Tube." Medical Engineering \& Physics 24 (2002): 572-586. 3 Jan. 2008 $<$ http://www.sciencedirect.com/science?_ob=ArticleURL\&_udi=B6T9K-46X7XFJ3\&_user=10\&_rdoc $=1 \& \_f m t=\& \_o r i g=s e a r c h \& \_s o r t=d \& v i e w=c \&$ acct $=C 000050221 \&$ version $=1$ \&_urlVersion=0\&_userid $=10 \& \mathrm{md} 5=8 \mathrm{c} 8 \mathrm{aa} 9 \mathrm{ddf} 286 \mathrm{f} 9 \mathrm{c} 2 \mathrm{ecde} 275 \overline{6} 11 \mathrm{c} 9 \mathrm{f} 25 \mathrm{e}>$

Lee, R. T. "Atherosclerotic Lesion Mechanics Versus Biology." Z. Kardiol 89 (2000): II/80-II/84. 31 Jan. $2008<$ http://mythic.lib.calpoly.edu:2133/content/pmgvt7fmfb4l08t2/>

Lee, RT, et al. "Structure-Dependent Dynamic Mechanical Behavior of Fibrous Caps from Human Atherosclerotic Plaques." Circulation 83 (1991): 1764-1770. 13 Feb. 2008 <http://circ.ahajournals.org/cgi/reprint/83/5/1764>

Li, Zhi-Yong, et al. "Atheroma: Is Calcium Important or Not? A Modelling Study of Stress within the Atheromatous Fibrous cap in Relation to Position and Size of Calcium Deposits." Conf Proc IEEE Eng Bio/ Soc. 3 (2005): 28 Jan. 2008 <http://mythic.lib.calpoly.edu:3765/xplore/down.html>

$\mathrm{Li}$, Zhi-Yong, et al. "Stress Analysis of Carotid Plaque Rupture Based on in vivo High Resolution MRI." Journal of Biomechanics 39 (2006a): 2611-2622. 8 Feb. 2008 $<$ http://www.sciencedirect.com/science?_ob=ArticleURL\&_udi=B6T82-4HDP7C5$4 \&$ user $=10 \&$ rdoc $=1 \&$ fmt $=$ \&_orig $=$ search \&_sort $=\mathrm{d} \& \mathrm{view}=\mathrm{c} \&$ acct $=\mathrm{C} 000050221 \&$ \&version $=1$ \&_urlVersion=0\&_userid $=10 \& \mathrm{md} 5=\mathrm{c} 3558 \mathrm{ce} 088 \mathrm{c} 3 \mathrm{a} 2 \mathrm{e} 44481 \mathrm{bfcc} 61 \mathrm{fecd} 29>$

Li, Zhi-Yong, et al. "How Critical is Fibrous Cap Thickness to Carotid Plaque Stability? A Flow-Plaque Interaction Model." Stroke 37 (2006b): 1195-1199. 28 Jan. 2008 <http://stroke.ahajournals.org/cgi/content/full/37/5/1195>

$\mathrm{Li}$, Zhi-Yong, et al. "Structural Analysis and Magnetic Resonance Imaging Predict Plaque Vulnerability: A Study Comparing Symptomatic and Asymptomatic Individuals." J Vasc Surg. 45 (2007a): 68-75. 15 Feb. 2008 <http://www.sciencedirect.com/science?_ob= ArticleURL\&_udi=B6WMJ-4N6Y5HR1\&_user=10\&_rdoc=1\&_fmt=\&_orig=search\&_sort= $\mathrm{d} \&$ view $=c \&$ acct $=\mathrm{C} 000050221 \&$ _version $=1 \&$ _urlVersion $=0 \& \_u s e r i \bar{d}=10 \& \mathrm{md} 5=6 \mathrm{cc} 6 \mathrm{baa} 98 \mathrm{f} 4 \mathrm{a} 08$ 5eefffdba0377235ac> 
Li Zhi-Yong, et al. "Does Calcium Deposition Play a Role in the Stability of Atheroma? Location may be the Key." Cerebrovasc Dis 24 (2007b): 452-459. 21 Feb. 2008

<http://www.karger.com/doi/10.1159/000108436>

Loree, Howard M., et al. "Effects of Fibrous Cap Thickness on Peak Circumferential Stress in Model Circumferential Stress in Model Atherosclerotic Vessels.” Circulation 71 (1992): 850-858. 28 Jan. 2008 <http://circres.ahajournals.org/cgi/reprint/71/4/850>

Loree, Howard M., et al. "Mechanical Properties of Model Atherosclerotic Lesion Lipid Pools." Atherioscler. Thromb. Vasc. Biol. 14 (1994): 230-234. 28 Jan. 2008 <http://atvb.ahajournals.org>

Maseri, Attilio, and Valentin Fuster. "Is there a Vulnerable Plaque?" Circulation 107 (2003): 20682071. 5 Feb. 2008 <http://circ.ahajournals.org/cgi/content/full/107/16/2068>

Mitsumori, Lee M. et al. "In vivo Accuracy of Multisequence MR Imaging for Identifying Unstable Fibrous Caps in Advanced Human Carotid Plaques." Journal of Magnetic Resonance Imaging 17 (2003): 410-420. 13 Feb. 2008 <http://mythic.lib.calpoly.edu: 2119/journal/104084084/abstract?CRETRY=1\&SRETRY=0>

Naghavi, Morteza, et al. "From Vulnerable Plaque to Vulnerable Patient: A Call for New Definitions and Risk Assessment Strategies: Part I." Circulation 108 (2003): 1664-1672. 4 Feb. 2008 $<$ http://circ.ahajournals.org/cgi/content/full/108/14/1664>

Nair, Anuja, et al. "Coronary Plaque Classification with Intravascular Ultrasound Radiofrequency Data Analysis." Circulation 106 (2002): 2200-2206. 26 Jan. 2008 <http://circ.ahajournals.org/cgi/content/full/106/17/2200>

Naghavi, Morteza, et al. "From Vulnerable Plaque to Vulnerable Patient- Part III: Executive Summary of the Screening for Heart Attack Prevention and Education (SHAPE) Task Force Report." Am J Cardio/ 98[suppl] (2006): 4 Feb. $2008<$ http://www.science direct.com/science?_ob=ArticleURL\&_udi=B6T10-4K4WFGW-1\&_user=10\&_rdoc= $1 \&$ fmt $=$ \&_orig=search\&_sort $=\mathrm{d} \& \mathrm{view}=\mathrm{c} \&$ _acct $=\mathrm{C} 000050221$ \&_version $=1$ \&_urlVersion $=0$ \&_use rid $=10 \& \mathrm{md} 5=3 \mathrm{~b} 92 \mathrm{ed} 9 \mathrm{a} 0 \mathrm{~d} 963547 \mathrm{e} 7 \mathrm{c} 60885$ beacc667>

Newman, Anne B., et al. "Coronary Artery Calcium, Carotid Artery Wall Thickness, and Cardiovascular Disease Outcomes in Adults 70 to 99 Years Old." Am J Cardiol 101 (2008): 186192. 25 Jan. $2008<$ http://www.sciencedirect.com/science?_ob= ArticleURL\&_udi $=$ B6T10-4RHDWYF-9\&_user $=10 \& \_r d o c=18 \_f m t=\&$ orig $=$ search\&_sort $=d \&$ view $=c \&$ acct $=C 000050221 \&$ _version=1\&_urlVersion=0\&_userid=10\&md5=99 $3 \mathrm{ffbe} 733 \mathrm{~d} 7 \mathrm{~b} 22 \mathrm{a} 8 \mathrm{~d} 2607283 \mathrm{e} 029 \mathrm{fdd}>$

O'Rourke "Mechanical Principles in Arterial Disease." Hypertension 26 (1995): 2-9. 13 Feb. 2008 $<$ http://hyper.ahajournals.org/cgi/content/full/26/1/2>

Richardson, Peter D., et al. "Influence of Plaque Configuration and Stress Distribution of Fissuring of Coronary Atherosclertoic Plaques." Atherosclerosis 96:1 (1989): 71-81. 7 May $2008<$ http://www.sciencedirect.com/science?_ob=ArticleURL\&_udi=B6T1B-49JXX6F$\mathrm{JF} \&$ user $=10 \&$ \& rdoc $=1 \& \_$fmt $=$\&_orig $=$search\&_sort $=\mathrm{d} \& \mathrm{view}=\mathrm{c} \& \_$acct $=$

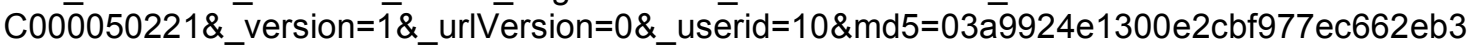
0ea5>

Salunke, N.V., et al. "Compressive Stress-Relaxation of Human Atherosclerotic Plaque." J Biomed Mater Res 55 (2001): 236-241. 3 Jan. 2008 <http://www3.interscience. wiley.com/journal/77001940/abstract?CRETRY=1\&SRETRY=0> 
Schulze-Bauer, C. A. J., and G. A. Holzapfel. "Determination of Constitutive Equations for Human Arteries from Clinical Data." Journal of Biomechanics 36 (2003): 165-169.

<http://www.sciencedirect.com/science?_ob=ArticleURL\&_udi=B6T82-47RB51J-

$3 \&$ user $=10 \&$ rdoc $=1 \&$ fmt $=$ \&_orig $=$ search \&_sort $=\mathrm{d} \& \mathrm{view}=\mathrm{c} \&$ acct $=\mathrm{C} 000050221 \&$ _version $=1$

\&_urIVersion=0\&_userid $=10 \& \mathrm{md} 5=a 2 b e 671 \mathrm{~d} 20512459145340 \mathrm{c} 7 \mathrm{dcb} 64569>$

Shaalan, Wael E, et al. "Degree of Carotid Plaque Calcification in Relation to Symptomatic Outcome and Plaque Inflammation." J Vasc Surg 40 (2004): 262-269. 3 Feb. 2008

$<$ http://www.sciencedirect.com/science?_ob=ArticleURL\&_udi=B6WMJ-4CXTKJ1-

D\&_user=10\&_rdoc $=1 \&$ fmt $=$ \&_orig $=$ search \&_sort $=d \& v i e w=c \&$ acct $=C 000050221$ \&_version $=1$ \&_urlVersion $=0$ \&_userid $=10 \&$ md $5=08 \mathrm{~b} 8 \mathrm{f} 18 \mathrm{fe}-\overline{4} 10 \mathrm{ee} 65751 \mathrm{e} 55 \mathrm{~d} 8871 \mathrm{e} 32 \mathrm{da}>$

Serfaty, Jean-Michel, et al. "Atherosclerotic Plaques: Classification and Characterization with T2weighted High-Spatial-Resolution MR Imaging-An in Vitro Study." Radiology 219 (2001): 403410. 26 Jan. $2008<$ http://radiology.rsnajnls.org/cgi/content/full/

$219 / 2 / 403>$

Shioi, A., et al. "Mechanism of Atherosclerotic Calcification." Clin Calcium 14:1 (2004): 133-9. 31 Jan. 2008 < http://mythic.lib.calpoly.edu:2086/CliCa0401133139?nosfx=y>

Sirineni, Gopi K.R., et al. "Calculation of Coronary Age Using Calcium Scores in Multiple Ethnicities." Int J Cardiovasc Imaging 24 (2008): 107-111. 13 Feb. 2008

<http://www.springerlink.com/content/5u7g6v615k2j1840/>

Sokolis, Dimitrios P., Harisios Boudoulas, and Panayotis E Karayannocos. "Assessment of the Aortic Stress-Strain Relation in Uniaxial Tension.” Journal of Biomechanics 35 (2002): 1213-1223. 28 Jan. $2008<$ http://www.sciencedirect.com/science?_ob=Article

URL\&_udi=B6T82-4607YCD-1\&_user $=10 \& \_r d o c=1 \& \_f m t=$ \&_orig=search\&_sort $=d$ \& view $=$ c $\&$ _acct $=C 000050221 \& \_$version $=1 \&$ urlVersion $=0 \&$ userid $=10 \& \mathrm{md} 5=63 \mathrm{~b} 58 \mathrm{fc} 93 \mathrm{cf} 2 \mathrm{de} 75 \mathrm{f}$ 7da9395f69beb2a>

Stary, Herbert C., et al. "A Definition of Advanced Types of Atherosclerotic Lesions and a Histological Classification of Atherosclerosis." Circulation 92 (1995a): 1355-1374. 25 Apr. 2008 <http://circ.ahajournals.org/cgi/content/full/92/5/1355>

Stary, Herbert C., et al. "A Definition of Advanced Types of Atherosclerotic Lesions and a Histological Classification of Atherosclerosis (Part II)." Circulation 15 (1995b): 1512-1531. 25 Apr. 2008 $<$ http://atvb.ahajournals.org/cgi/content/full/15/9/1512>

Stary, Herbert C. "Reevaluation Natural History and Histological Classification of Atherosclerotic Lesions: An Update." Atherioscler Thromb Vaxc Biol. 20 (2000): 1177-1178. 26 Jan. 2008 $<$ atvb.ahajournals.org>

Stary, H.C. "Natural History of Calcium Deposits in Atherosclerosis Progression and Regression." Z Kardiol 89:Suppl 2 (2000): II/28-II35. 31 Jan. 2008

<http://atvb.ahajournals.org/cgi/content/full/20/5/1177>

Tang, Dalin, et al. "Quantifying Effects of Plaque Structure and Material Properties on Stress Distributions in Human Atherosclerotic Plaques Using 3D FSI Models." J Biomech Eng. 127:7 (2005): 1185-1194. 28 Jan. 2008 < http://www.pubmedcentral.nih.gov/ articlerender .fcgi?tool=pubmed\&pubmedid=16502661>

Tang D., et al. "3D MRI-Based Multicomponent FSI Models for Atherosclerotic Plaques." Annals of Biomedical Engineering 32:7 (2004): 947-960. 5 Feb. 2008 <http://www.springerlink.com/content/ht47x94437k83136/> 
Tang, Tjun Y., et al. "Comparison of the Inflammatory Burden of Truly Asymptomatic Carotid Atheroma with Atherosclerotic Plaques Contralateral to Symptomatic Carotid Stenosis: An Ultra Small Superparamagnetic Iron Oxide Enhanced Magnetic Resonance Study." J Neurol Nerosurg Psychiatry 78 (2007): 1337-1343. 15 Feb. $2008<$ http://www.sciencedirect.com/science?_ob=ArticleURL\&_udi=B6WF5-4RGVWJH2\&_user=10\&_rdoc $=1 \&$ fmt $=$ \&_orig=search\&_sort $=\mathrm{d} \&$ view $=\mathrm{c} \&$ acct $=\mathrm{C} 000050221 \&$ _version $=1$ \&_urlVersion $=0$ \&_userid $=10 \& \overline{m d} 5=d 7 c 9 b e b c \overline{4} a 3873 c c 57 e 80 \mathrm{da} 2704 a a 45 b>$

Tang T.Y, et al. "Correlation of Carotid Atheromatous Plaque Inflammation with Biomechanical Stress: Utility of USPIO Enhanced MR Imaging and Finite Element Analysis." Atherosclerosis 196 (2008): 879-887. 8 Feb. 2008 <http://stroke.ahajournals.org/cgi/reprint/STROKEAHA.107.504753v1>

Toussaint, Jean-Francois, et al. "Behavior of Atherosclerotic Plaque Components After in vitro Angioplasty and Atherectomy Studied by High Field MR Imaging." Magnetic Resonance Imaging 16:2 (1998): 175-183. 4 Jan. 2008 < http://www.sciencedirect.com/ science?_ob=ArticleURL\&_udi=B6T9D-3ST7H3N-9\&_user=10\&_rdoc=1\&_fmt $=$ \& orig=search\&_sort $=\mathrm{d} \& \mathrm{view}=\mathrm{c} \&$ acct $=\mathrm{C} 000050221$ \&_version $=1 \&$ _urlVersion $=0$ \&_userid $=10 \& \mathrm{md}$ $5=95 \mathrm{a} 7 \mathrm{~d} 6 \mathrm{~b} 047 \mathrm{~b} 6 \mathrm{ecf} 20 \mathrm{df} 3 \mathrm{c} 701 \mathrm{9} 2427 \mathrm{f} 82>$

Toussaint, Jean-Francois, et al. "Magnetic Resonance Images Lipid, Fibrous, Calcified, Hemorrhagic, and Thrombotic Components of Human Atherosclerosis in vivo." Circulation 94 (1996): 932-938. 13 Feb. 2008 <http://circ.ahajournals.org/cgi/content/full/94/5/932>

Trivedi, Rikin A., et al. "Identifying Vulnerable Carotid Plaques in vivo Using High Resolution Magnetic Resonance Imaging-Based Finite Element Analysis." J Neurosurg 107 (2007): 536-42. 15 Feb. 2008 < http://thejns.org/doi/abs/10.3171/JNS-07/09/0536 >

Veress, A. I., et al. "Vascular Mechanics of the Coronary Artery." Z Kardiol 89:Suppl 2 (2000): II/92II/100. 31 Jan. $2008<$ http://mythic.lib.calpoly.edu:2133/content/ II2gph8apxh3xqxd/>

Virmani, Renu, et al. "Lessons from Sudden Coronary Death: A Comprehensive Morphological Classification Scheme for Atherosclerotic Lesions." Aterioscler. Thromb. Vasc. Biol. 20 (2000): 1262-75. 26 Jan. $2008<$ http://atvb.ahajournals.org/ cgi/content/full/20/5/1262> 